Measurement

Manuscript Number: MEAS-D-18-01717R1

Title: The Role of Hardness on Condition Monitoring and Lifing for High Temperature Power Plant Structural Risk Management

Article Type: Letter to the Editor

Keywords: Hardness; Creep; Replica; Damage Model; Condition Monitoring Corresponding Author: Dr. Bianca Cacciapuoti,

Corresponding Author's Institution: University of Nottingham

First Author: Andy Morris

Order of Authors: Andy Morris; Bianca Cacciapuoti; Wei Sun 
Dear Editor,

We are pleased to resubmit for publication the revised version of the paper under Manuscript ID MEAS-D-17-02052 "The Role of Hardness on Condition Monitoring and Lifing for High Temperature Power Plant Structural Risk Management Measurement".

We appreciated very much the most constructive and valuable comments made by the reviewers. In the revised manuscript, the changes based on the comments made by Reviewer 1 and 2 have been highlighted in yellow and in green, respectively.

Thank you very much.

Yours sincerely,

The authors (A. Morris, B. Cacciapuoti, W. Sun) 


\section{Answers to Referees}

\section{Reviewer \#1}

\section{August 2018}

The manuscript was improved and my questions were revised satisfactorily. However, the author should state the logical relation among Sections 2,3,4, and 5.

The logical relation among Sections 2, 3, 4, and 5 is now included in Section 1 (Introduction) of the revised paper as per follow:

The paper discusses interpretation techniques of hardness data and it identifies improvement possibilities with particular focus on applications in lifing models. In particular, standard hardness tests and their current status of application are described in Section Error! Reference source not found.. Correlation of hardness data with creep life, by use of the most established methods, is discussed in Section Error! Reference source not found., while Section 4 shows how such correlations are not capable to produce robust estimations of the creep life for a high temperature component. Therefore, the need for a novel methodology arises, which is addressed in Section 5, where the validation of such novel technique is also presented.

\section{July 2018}

The paper provided large amount of data of Creep void and hardness, and established the relationship between hardness and creep voids and creep strain rate. The result carried out the base of measurement of creep life of high temperature power pipes with important engineering value. It can guidance the power structural risk management and I like to recommend to publish in this Journal.

However, there may be some revision or explanation:

(1) in 5.1 Paragraph, the hot reheat line with temperature at 368 cent degree, maybe no in the creep time (lower than the temperature for the steel can creep occur)

The Referee is correct. In the revised manuscript this typo error has been corrected to $568{ }^{\circ} \mathrm{C}$.

(2) In Paragraph, there is 5.1.1, but there in no 5.1.2,etc.

The referee is correct. The typo error has been corrected in the revised manuscript and Section 5 is now divided in 5.1, 5.2 and 5.3.

(3) In Paragraph 5.1, the relation between hardness and creep cavities was given, however, in the following discussion in 5.2 and 5.3, only creep was related but not hardness.

In the revised manuscript, Paragraph 4.2 shows and discusses the change in parent hardness (figure 2) and the corresponding creep cavity count (figure 3) over two 
successive outages. These data show there is no clear correlation between change in hardness and the creep cavity count in-service'

(4) In paragraph 6.1, hardness increases with increases of creep strain rate (increasing servicing time), however, the hardness decreases with servicing time due to creep void. It is mean that hardness will increase then decrease with servicing time?

Hardness will decrease with servicing time; that is why equations (22) and (23) can be used for monitoring. Test data presented in Figure 6 show that hardness decreases with increasing minimum creep strain rate (MSR). MSR is constant with time by mathematical definition under "steady-state" assumption, but in reality it is not. Therefore, decrease in hardness during service history, indicates an increase in MSR and therefore a decrease in time to failure, meaning that the component may need to be repaired or replaced. Equations (22) and (23) can be used for monitoring because they take in input the current hardness value and give in output the current creep strain and the current time to failure.

This is now explained in section 5.1 of the revised manuscript.

(5) in Paragraph 5.1.1, "the creep cavitation tends to peak at the outer surface"--if any evidence or references can test this (because creep cavitation maybe occur inside the wall, not in the out sruface).

This is confidential information kindly provided by EDF Energy (West Burton Power) Limited, and, as pointed out by the Referee, it is not a general rule, but only an observed trend. This is now clarified in the revised manuscript (new ref. [36]).

(6) what is the purpose of 6.2 and 6.3 ?

Section 6.2: in the submitted manuscript was already clarified that the determination of Liu and Murakami's damage model material constants is well described in [46] and it is reported only for the reader's convenience.

Section 6.3 seeks to describe a practical way to use equations (22) and (23) for monitoring purposes.

\section{Reviewer \#2}

\section{July 2018}

1. The paper is not clear in terms of objectives. Is it a research paper or review paper?

It is a research paper. The objectives have now been clarified in the Introduction of the revised manuscript as per follow:

The aims of the papers are to: 
a. Present a case study to show that the massive amount of hardness data routinely collected by power plant utilities are not enough to determine components failure life, even though they are used in conjunction with other techniques, such as surface replica count;

b. Present a novel relationship between hardness and creep strain rate useful for monitoring purposes.

2. However remove section 2 (background) and all old references.

Section 2 (Historical background) and all the old references have been removed in the revised manuscript as per Referee request.

3. If it is a research paper, please, display a table of data to be used for determining the hardness according to the goals of your paper.

Determining hardness is not the scope of the submitted manuscript. However, hardness data can be used as an input in equations (22) and (23) in order to obtain the current creep strain and the current time to failure for monitoring purposes. This is now clarified in the updated manuscript. 
The Role of Hardness on Condition Monitoring and Lifing for High Temperature Power Plant Structural Risk Management

A. Morris ${ }^{A}$, B. Cacciapuoti ${ }^{B *}$, W. Sun ${ }^{B}$

A EDF Energy (UK), Coal Gas and Renewables, Central Technical Organisation, Barnwood, Gloucester GL4 3RS UK

B Department of Mechanical, Materials and Manufacturing Engineering, University of Nottingham, Nottingham NG7 2RD UK

\section{Abstract}

In this work, the use of hardness data in a novel predictive lifing model is explored. This study provides for the first time large amounts of site hardness data acquired during successive outages on an ageing coal fired power plant and draws conclusions regarding interpretation of these data in accordance with current practice, which is included in a case study. A novel, phenomenological relationship between room temperature hardness and creep data, obtained by uniaxial creep and impression creep tests, has been found and used for an innovative lifing approach that includes hardness data in a creep damage model. The latter is discussed with a description of how it could be practically implemented and validated inservice.

Keywords: Hardness; Creep; Replica; Damage Model; Condition Monitoring.

*Corresponding Author: bia.cacciapuoti@gmail.com

\section{Nomenclature}

$\begin{array}{ll}a & \text { Fitting constant } \\ A & \text { Curved area of indentation in Brinell standard test } \\ b & \text { Fitting constant } \\ b_{I} & \text { Length of impression creep sample } \\ B & \text { Material constant } \\ C & \text { Material constant in Monkman-Grant's relationship } \\ D & \text { Material constant in Liu and Murakami's model } \\ d & \text { Length of diagonal } \\ d_{I} & \text { Width of impression creep indenter } \\ e & \text { Neper's number } \\ G & \text { Material constant in Allen and Fenton's model }\end{array}$


$h_{I} \quad$ Thickness of impression creep sample

H Hardness

$H B \quad$ Brinell hardness number

HK Knoop hardness number

HV Vickers hardness number

$H_{0} \quad$ Initial hardness

$K_{s} \quad$ Fitting constant in Masuyama's model

LMP Larson-Miller parameter

$m \quad$ Material constant in Monkman-Grant's relationship

MSR Minimum creep strain rate

n Material constant

$N \quad$ Strain-hardening exponent

p Contact pressure

$P \quad$ Applied load

$q \quad$ Fitting constant in Allen and Fenton's model

$q_{2} \quad$ Material constant in Liu and Murakami's model

$Q \quad$ Activation energy

$R \quad$ Gas constant

$s \quad$ Normalising parameter

S Flow strength

$t \quad$ Time

$t_{r} \quad$ Time to rupture

T Absolute temperature

$w_{I} \quad$ Width of impression creep sample

$\Delta \varepsilon_{i}^{c} \quad$ Creep strain increment at time step $i$

$\Delta t \quad$ Time increment

$\varepsilon^{c} \quad$ Creep strain

$\dot{\varepsilon}_{\min }^{c} \quad$ Minimum creep strain rate

$\sigma \quad$ Stress

$\sigma_{E Q} \quad$ Equivalent stress

$\sigma_{y} \quad$ Yield stress

$\sigma_{U T S} \quad$ Ultimate tensile stress

$\chi \quad$ Material constant in Liu and Murakami's model

$\omega, \dot{\omega} \quad$ Damage variable and damage rate 


\section{Introduction}

Surface hardness is a non-destructive technique, often used during plant outages or other offload periods to acquire broad intelligence on the condition of the material in-service at high temperature. One of the attractions of the technique is that it can be deployed relatively easily and widespread across a power plant. Invariably the capture of hardness data is accompanied with other procedures such as surface replicas. Often the hardness and surface replica data is assessed together in order to direct a suitable course of action to ensure that the plant is safe to operate over the next period.

As materials age in service at high temperatures the expectation is that the hardness will reduce and in addition the surface replica will also show a change in condition, usually interpreted as a measurement or count of the amount of creep cavities per unit area. The general approach to site assessment procedures is reviewed elsewhere [1]. The paper discusses interpretation techniques of hardness data and it identifies improvement possibilities with particular focus on applications in lifing models. In particular, standard hardness tests and their current status of application are described in Section 2. Correlation of hardness data with creep life, by use of the most established methods, is discussed in Section 3, while Section 4 shows how such correlations are not capable to produce robust estimations of the creep life for a high temperature component. Therefore, the need for a novel methodology arises, which is addressed in Section 5, where the validation of such novel technique is also presented.

\section{The aims of the paper are to}

a. Present a case study to show that the massive amount of hardness data routinely collected by power plant utilities are not enough to determine components failure life, even though they are used in conjunction with other techniques, such as surface replica count;

\section{b. Present a novel relationship between hardness and creep strain rate useful for monitoring purposes.}

The provided case study regards an ageing $0.5 \% \mathrm{Cr} 0.5 \% \mathrm{Mo} 0.25 \% \mathrm{~V}$ steel (CMV) that is based on several hundred hardness and surface creep replica data points obtained during successive outages from a large coal fired power station. 
The authors recently published a paper, "The Role of Small Specimen Creep Testing within a Life Assessment Framework for High Temperature Power Plant" [1], which focuses on the development of a novel life management framework and how to use the small specimens data for more informed assessment.

The provided novel approach that implements hardness data in a creep life model for a grade P91 steel has been developed by the authors and a commentary on how this method could be deployed in practice is also provided. In fact, an empirical relationship between hardness and minimum creep strain rate has been established and, for the first time, implemented in a modified Liu and Murakami model in order to assess the material failure life.

\section{Interpretation of Hardness Data}

In this section, attention is only paid to static hardness tests carried out at room temperature.

\subsection{Theoretical Background}

The standard Brinell test is carried out by applying a static load, $P$, in kgf, for 30 s on a spherical indenter made of hard steel, which compresses a sample in its normal direction. The Brinell hardness number $(H B)$ has the dimensions of a pressure and, in the absence of friction between the specimen and the punch, is expressed by equation (1), where $A$ is the curved area of indentation, in $\mathrm{mm}^{2}[2,3]$. In defining the $\mathrm{HB}$, Brinell first included in equation (1) the projected area of indentation, but this caused variations in the hardness measurements due to indentation size effects $[2,3]$.

$H B=\frac{P}{A}$

Standard Brinell test cannot evaluate the hardness for those materials which present hardness higher than about $400 \mathrm{HB}$, therefore Smith and Sandland [2, 3] proposed the Vickers test in 1925, which makes use of a square based diamond as indenter, and gives the same hardness number as the Brinell test. As expressed in equation (2), Vickers number, $H V$, is given by the ratio of the applied load in grams-force, and the pyramidal area of indentation, where $d$ is the length of diagonal in $\mu \mathrm{m}$. The angle between two diagonals of the pyramid is $136^{\circ}$, whilst $H V$ is generally expressed in $\mathrm{kgf} / \mathrm{mm}^{2}$ [3]. Vickers test has the essential advantage of being able to assess the hardness of any material and to locate it on one continuous scale [3]. Figure 1 shows (a) the standard Vickers indenter, (b) the indentation produced, and (c) the plastic flow in the indentation area. 


$$
H V=1854.4 \frac{P}{d^{2}}
$$

In 1939 Knoop et al. developed a test similar to Vickers, particularly helpful in the evaluation of very thin materials and in the estimation of the effects of the orientation of crystals on hardness [2, 3]. In Knoop test the indenter has the shape of an elongated pyramid and its number, $H K$, is given by equation (3).

$$
H K=14229 \frac{P}{d^{2}}
$$

The fastest hardness test, that also has the advantage of involving depth measurements instead of optical measurements, is the Rockwell test, but a worldwide unified hardness scale still does not exist, even if a step forward has been done by Song et al. in order to overcome this problem [2-4].

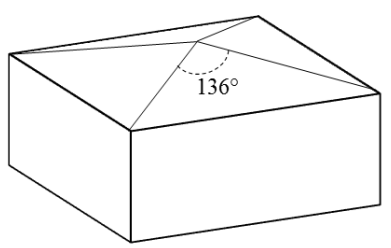

(a)

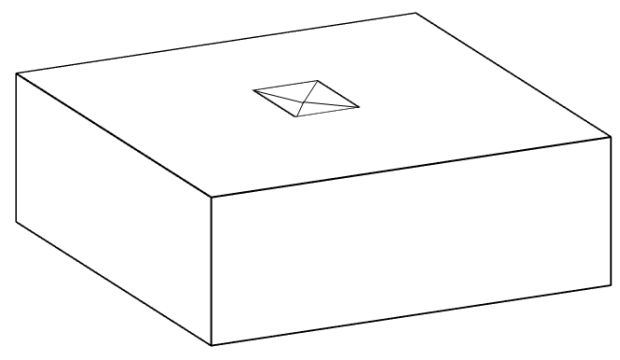

(b)

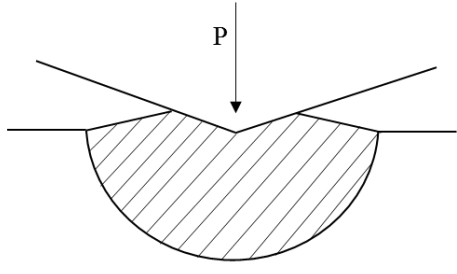

Plastic Zone

(c)

Figure 1. (a) Standard Vickers diamond pyramid indenter, (b) the indentation it produces, and (c) the plastic flow around the indentation, adapted from ref. [2].

As a general rule for obtaining a successful hardness value among the described ones, the specimen must be much larger than the indentation and every indentation must be carried out at a distance of at least $3 d$ or $4 d[2,3]$. Friction should also be considered, as it has been proved to affect the test, especially at very low loads [3].

\subsection{Empirical Relations between Hardness and Yield Strength}

By considering the hypotheses of isotropic material, fully work-hardened behaviour, constant yield stress, $\sigma_{y}$, and negligible elastic deformation, and keeping into account that the hydrostatic part of the stress tensor does not concur to plastic flow, it has been demonstrated that the mean contact pressure, $p$, between the specimen and the indenter is given by equation (4) $[3,5-7]$.

$p \cong 3 \sigma_{y}$

The uniaxial flow strength, $S$, is related to hardness by equation (5), where $c$ is an elastic constraint factor equal to 3 for metals that do not significantly strain harden when $\mathrm{HV}$ is 
measured in $\mathrm{kg}_{\mathrm{f}} / \mathrm{mm}^{2}$ and $S$ in $\mathrm{MPa}[6,8-10]$.

$H V=c S$

The plastic strain related to $S$ only depends on the geometry of the indenter tip and is 0.08 for a diamond pyramid hardness test $[8,11]$.

The ultimate tensile stress, $\sigma_{\text {UTS }}$, and the yield stress are related to hardness through the Cahoon et al. relationships (equations (6) and (7)), where $N$ is the strain-hardening exponent $[12,13]$.

$\sigma_{U T S}=\frac{H V}{2.9}\left(\frac{N}{0.217}\right)^{N}$

$\sigma_{y}=\frac{H V}{3}(0.1)^{N}$

The tensile properties of ferritic steels can be accurately calculated by equations (6) and (7) at temperatures up to $400{ }^{\circ} \mathrm{C}$ if the strain-hardening exponent is known by previous uniaxial tensile tests [14].

\subsection{Current Status of Applications}

Surface hardness measurements take place during off-load monitoring of power plant components, together with pipe movement checks, passive strain measurements, surface creep replicas and material composition checks, but, nowadays, they cannot be routinely used as an input into a predictive creep life assessment of the piping system [1], especially because the scatter in the measured data can be large. Furthermore, hardness measurements are highly affected by microstructural variations, which cause concerns during condition monitoring of welds [15-18]. Currently, utilities adopt hardness technique as part of the quality assurance tests in order to evaluate microstructural quality of components and in-service trends, while the Electric Power Research Institute (EPRI) provides guidelines and perspectives on the use of hardness testing [19-22]. However, hardness and micro-hardness tests application is not limited to power plant issues. In fact, in 2009, Infante et al. used those two techniques to investigate the possible causes of the failure of aero-engine compressor blades [23].

\section{Hardness Based Lifing Models}

The research of a correlation between hardness data and time temperature parameters has 
been ongoing since 1943 [24, 25]. A modified Kachanov's damage model that includes hardness and the effects of structural degradation and creep cavitation was developed by Cane et al. in 1985 [26, 27]. Their method is able to predict upper and lower boundaries for the time to rupture, but many material constants and parameters, including hardness due to solid solution strengthening, need to be determined or measured, making this approach of little practical use.

In 2006, Masuyama found the following relationship, equation (8), between the remaining life, $t_{r}$, for $9 \mathrm{Cr}-\mathrm{Mo}-\mathrm{V}-\mathrm{Nb}$ steel and the changes in hardness, expressed as the ratio of the hardness of the crept specimens, $H$, and the initial hardness, $H_{0}$ [16].

$\frac{H}{H_{0}}=0.98-0.15 \frac{t}{t_{r}} \Rightarrow \frac{t}{t_{r}}=\frac{1}{0.15}\left(0.98-\frac{H}{H_{0}}\right)$

By assuming the initial drop in hardness to be zero, Masuyama also established a relationship between the drop in hardness and the Larson- Miller parameter (LMP), as shown in equation (9), where $K_{s}$ is a fitting constant, $t$ the time in hours and $T$ the absolute temperature [28, 29].

$\ln \left(H_{0}-H\right)=K_{S}(L M P)=K_{S} T(20+\log t)$

From equation (9) Masuyama expressed $H_{0}$ and the remaining life as a function of the Larson-Miller parameter, as reported in equations (10) and (11) [28].

$H_{0}=H+\exp \left[K_{S} T(20+\log t)\right]$

$\frac{t}{t_{r}}=\frac{1}{0.15}\left(0.98-\frac{H}{H+\exp \left[K_{s} T(20+\log t)\right]}\right)$

Many researchers base their models for creep life evaluation on hardness as a function of the Larson-Miller parameter [17, 30, 31]. In particular, Furtado et al. have correlated the LarsonMiller parameter and the changes in hardness for a particular material, but their method only provides a first evaluation of damage if the initial hardness of the material is known at time $t=0$ hours, and cannot be used for establishing the damage and the remaining life of welds [29, 32-34]. Mukhopadhyay et al. also emphasised the necessity of considering a different non-linear correlation between hardness and LMP, based on experimental observations [31]. For ductile materials, equation (12) relates the failure time, $t_{r}$, to the applied stress, $\sigma$, where $B$ and $n$ are material constants $Q$ is the constant activation energy and $R$ the gas constant [35]. In 2007, Allen and Fenton, starting from equation (12), derived a practical normalised hardness-based stress model to predict the failure life of new and service aged P91 steel [35]. 
Their method is here given in equations (13) and (14), where $G$ and $q$ are a material and a fitting constant respectively, and $s$ is a normalising parameter defined as the ratio between the applied stress and the flow stress. The latter is in turn defined as the average of the $0.2 \%$ proof stress and the ultimate tensile stress.

$t_{r}=B \sigma^{-n} \exp \left(\frac{Q}{R T}\right)$

$B \sigma^{-n}=G\left(s / H V^{-q n}\right)$, with $q>1$

$\ln \left(t_{r}\right)-\left(\frac{Q}{R T}\right)=\ln (G)-n \ln (S)+q n \ln (H V)$

The fitting constant $q$ has been introduced by Allen and Fenton to take into account the possible non-linear correlation between creep strength and high temperature tensile strength or the possible non-linear relationships between high temperature tensile properties and room temperature tensile and hardness properties [35]. This method is of practical use, but underestimates the failure life and overestimates $Q$ and $n$, therefore it should be improved by considering the flow stress as temperature dependent [35].

\section{Hardness and Surface Replica Data - Industrial Practice Case Study}

Despite some hardness lifing models have been developed so far, as described in Section 3, there is no universally applied and accepted hardness based material life model currently in use. Various plant service organisations routinely capture hardness data as part of periodic plant outage campaigns and usually in conjunction with data obtained from other examination techniques such as surface replicas. The use of hardness in a lifing model can be contemplated for scenarios such as supporting safety case assessments [35], but noting that such safety cases are invariably complemented by data acquired from several other examination techniques and periodic measurements [1].

Currently hardness testing on operational plant is undertaken to provide general surveillance data, essentially to track trends over time and with limiting values defined based on practical experience. The benefits of this approach are that a relatively large number of plant locations can be cost-effectively sampled during a plant outage. However, a key aspect of this approach is the identification of the rate of change in hardness over time. Hardness testing is complemented by interrogation of other plant data such as operating temperatures, surface replicas, non-destructive testing results, etc. 
The following case study will discuss the hardness data trends, correlation with surface replicas and provides an overview on how subsequent operational risk is managed throughout life on parent CMV main steam lines in-service on a conventional fossil-fired power station.

\subsection{Plant Conditions}

Data from the four main steam and four hot reheat lines on one 500MW boiler are considered in this case study. The main steam lines transport steam from the boiler outlet header to the high pressure steam turbine, with nominal design operating conditions of $568{ }^{\circ} \mathrm{C}$ and 165.5bar. The main steam lines are approximately $350 \mathrm{~mm}$ outer diameter with a nominal wall thickness of $65 \mathrm{~mm}$, which equates to a mean diameter hoop stress of $36 \mathrm{MPa}$ at the nominal design pressure. The hot reheat lines transport steam from the boiler reheater to the intermediate pressure turbine, with nominal design operating conditions of $568^{\circ} \mathrm{C}$ and $41 \mathrm{bar}$. The hot reheat lines are approximately $500 \mathrm{~mm}$ outer diameter with a wall thickness of $27 \mathrm{~mm}$, which equates to a mean diameter hoop stress of $36 \mathrm{MPa}$ at the nominal design pressure.

It is worth noting that typical operation involves multiple plant starts with some overshoot of the nominal design operating temperature; other reference papers [1] provide further information on plant historical operation on this particular station and steam line specific transient operating conditions.

For this case study on CMV main steam and hot reheat lines hardness data has been collated over two successive outages, separated by 4 years, as outlined in Table 1.

Table 1. Unit hours and unit starts for two successive outages.

\begin{tabular}{|c|c|c|}
\cline { 2 - 3 } \multicolumn{1}{c|}{} & Outage 1 & Outage 2 \\
\hline Unit hours & $239.649 \times 10^{3}$ & $259.733 \times 10^{3}$ \\
\hline Unit starts & 3425 & 3971 \\
\hline
\end{tabular}

\subsection{Hardness and Creep Replica Data}

The number of pipework locations examined during both outage 1 and outage 2 is summarised in Table 2. For each of these locations both surface creep replicas and hardness measurements were obtained; noting that this just covers the examination of parent material. 
Table 2. Number of Hardness and Creep Replica data points of the parent material.

\begin{tabular}{|c|c|c|}
\cline { 2 - 3 } \multicolumn{1}{c|}{} & Outage 1 & Outage 2 \\
\hline Main steam & 146 & 408 \\
\hline Hot reheat & 79 & 663 \\
\hline
\end{tabular}

It should be emphasised that the above only represents parent material hardness and creep replica data from one of the four 500MW boilers operating at the station. There are at least as many hardness and creep replica data points for the weldments covering both the weld metal and heat affected zones.

There are a number of portable tools that can be used to capture surface hardness, using a range of methods such as impedance, direct measurement, ultrasonic contact or dynamic rebound. The Equotip system is commonly used for site measurements and interrogates the impact and dynamic rebound velocities to determine the surface hardness value. As with all measurements the initial preparation is important; for surface hardness measurements it is necessary to remove any hard surface scale prior to measurement, also it is usual to capture a number of readings and report a single mean value as the measurement. The corresponding creep replicas are classified in this particular study based on the assessment levels defined in Table 3.

Table 3. Creep replica assessment levels.

\begin{tabular}{|c|c|c|}
\hline $\begin{array}{c}\text { Creep replica } \\
\text { assessment level }\end{array}$ & Definition & $\begin{array}{c}\text { Creep cavities per } \\
\mathbf{m m}^{\mathbf{2}}\end{array}$ \\
\hline 1 & Clear & 0 \\
\hline 2 & Very isolated & $1-10$ \\
\hline 3 & Isolated & $10-50$ \\
\hline 4 & Low orientated & $50-250$ \\
\hline 5 & $\begin{array}{c}\text { Orientated (Including } \\
\text { high orientated) }\end{array}$ & $250-500$ \\
\hline 6 & Grouped & $500-1000$ \\
\hline 7 & Aligned & $1000-1500$ \\
\hline
\end{tabular}

Figure 2 (a) and (b) show the sample variation in hardness for parent main steam for outage 1 and 2, respectively, and Figure 2 (c) and (d) show the sample variation in hardness for parent hot reheat pipework material for outage 1 and 2, respectively. Typically, a start of life Hardness $\mathrm{HV}$ value for $\mathrm{CMV}$ is $\sim 170 \mathrm{HV}$, hence extended service life results in a significant 
reduction in hardness. Table 4 gives the sample means and standard deviations for the two outage populations, a general reduction in hardness level is evident between these two outage samples.

Table 4. Hardness sample statistics (in HV).

\begin{tabular}{|c|c|c|c|c|}
\cline { 2 - 5 } \multicolumn{1}{c|}{} & \multicolumn{2}{c|}{ Main Steam } & \multicolumn{2}{c|}{ Hot Reheat } \\
\cline { 2 - 5 } \multicolumn{1}{c|}{} & Mean & $\begin{array}{c}\text { Standard } \\
\text { Deviation }\end{array}$ & Mean & $\begin{array}{c}\text { Standard } \\
\text { Deviation }\end{array}$ \\
\hline Outage 1 & 132.91 & 9.95 & 139.73 & 10.42 \\
\hline Outage 2 & 125.05 & 7.69 & 132.87 & 8.33 \\
\hline
\end{tabular}

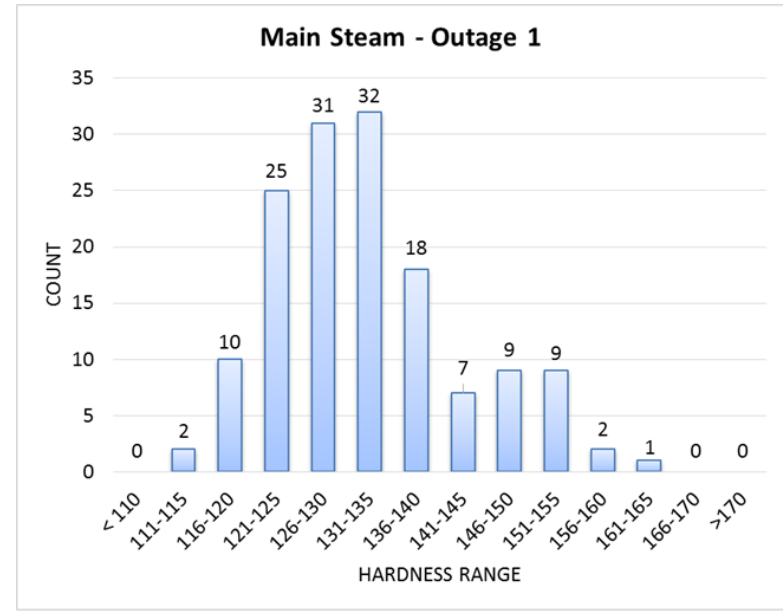

(a)

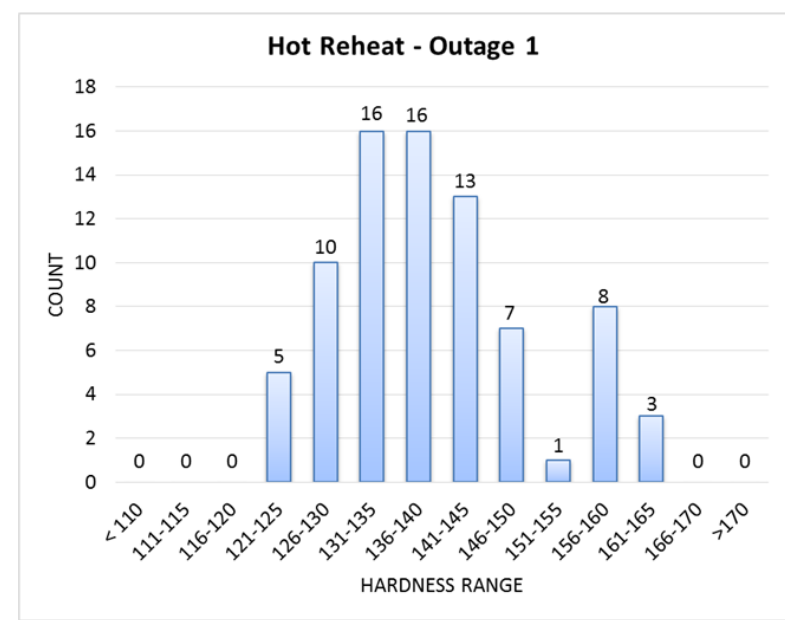

(c)

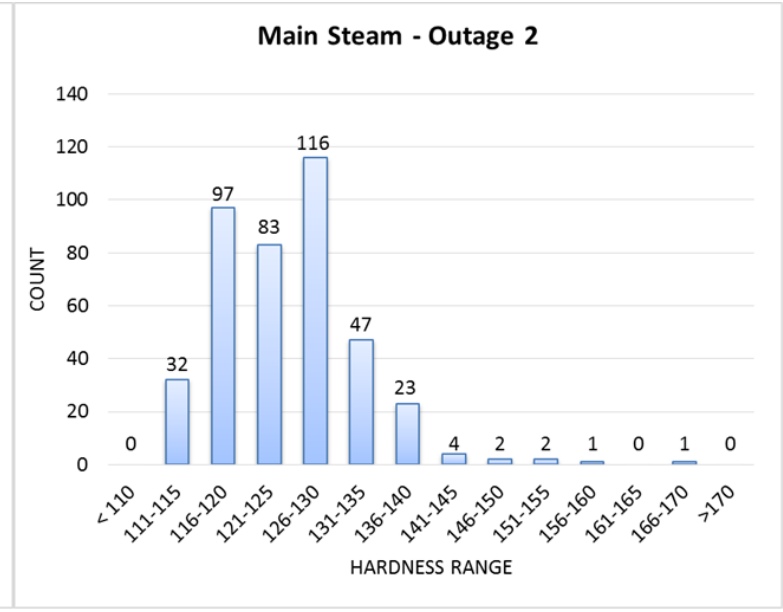

(b)

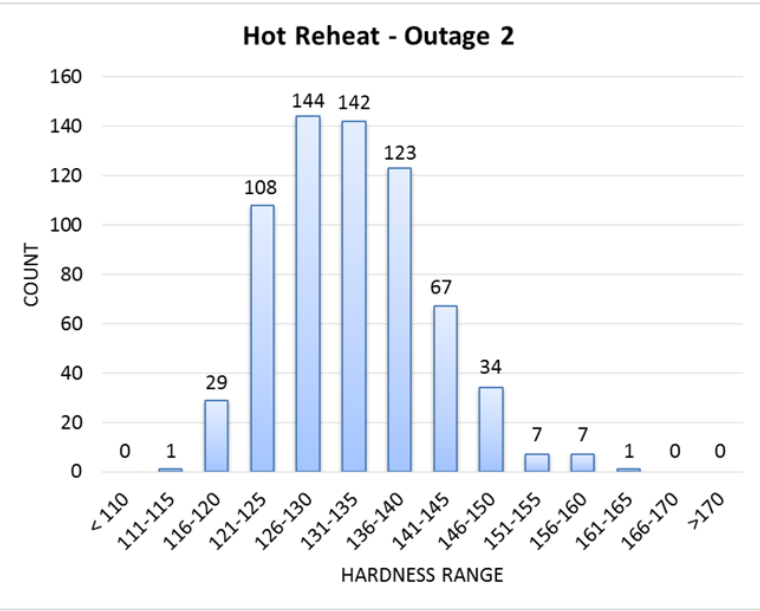

(d)

Figure 2. Hardness range for Main Steam for (a) Outages 1 and (b) Outages 2; hardness range for Hot Reheat pipework for (c) Outages 1 and (d) Outages 2 .

Figure 3 compares, for each hardness reading, the associated surface creep replica assessment level; in particular Figure 3 (a) and (b) are related to the main steam for outage 1 and 2, respectively, and Figure 3 (c) and (d) to the hot reheat pipework material for outage 1 and 2, 
respectively. There is no clear correlation between the respective hardness values and the assessed creep replica level. Unpublished information [36] describing the sectioning of similar ex-service parent pipework and through thickness creep replication studies from sister units of similar age and pedigree have shown that generally the creep cavitation tends to peak at the outer surface or just below, with a progressive and significant reduction through wall. However, this is not a general rule, as observed for example in [37, 38].

Importantly, in these data sets, when comparing successive hardness and creep replica data from the same location it is apparent that there is a greater probability of identifying a change in the hardness level as opposed to a change in the creep replica assessment level.

Typically, during such a site assessment, intelligence gleaned from examination of the surface replicas is often used as the leading indicator to determine subsequent re-inspection intervals or replacement and repair options. The hardness data is used primarily as a back-up measurement, which may or may not correlate with a trend of gradual in-service degradation over time. In this particular case study the hardness data is (for the population) showing a general deterioration between the two outages, whereas there is little correlation between the change in hardness level and the assessment of the creep cavity count. This in itself provides the challenge for parent material, especially since the through section studies on retired pipe sections have shown only surface creep damage, with very limited evidence of further creep cavitation through the majority of the remaining pipe section. 


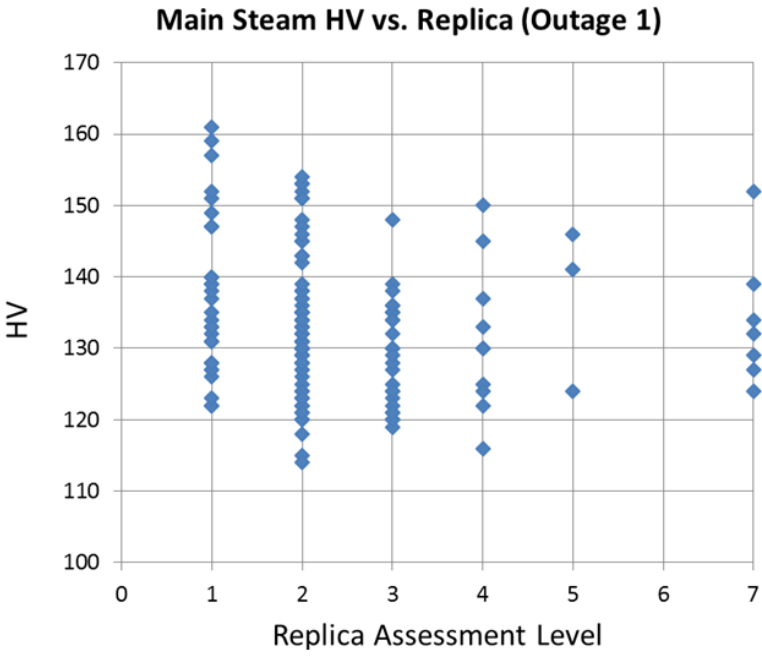

(a)

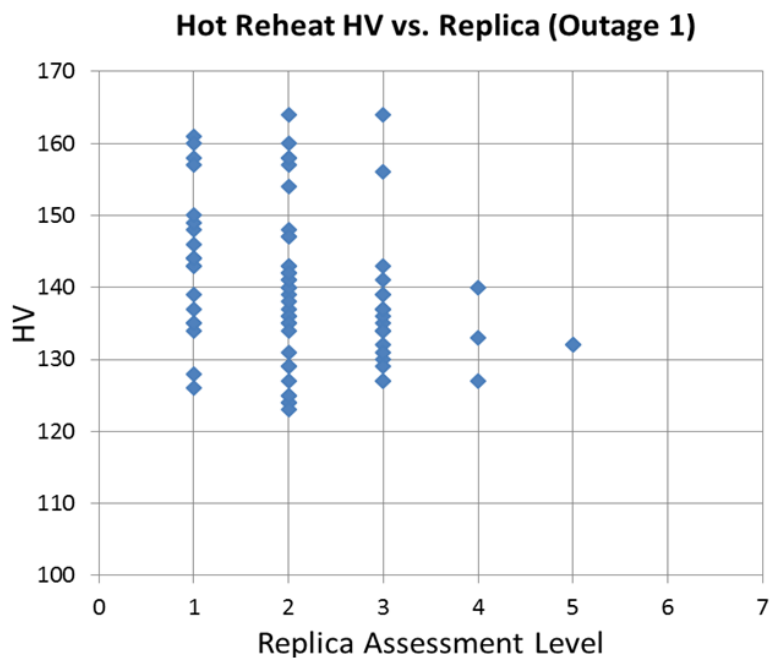

(c)

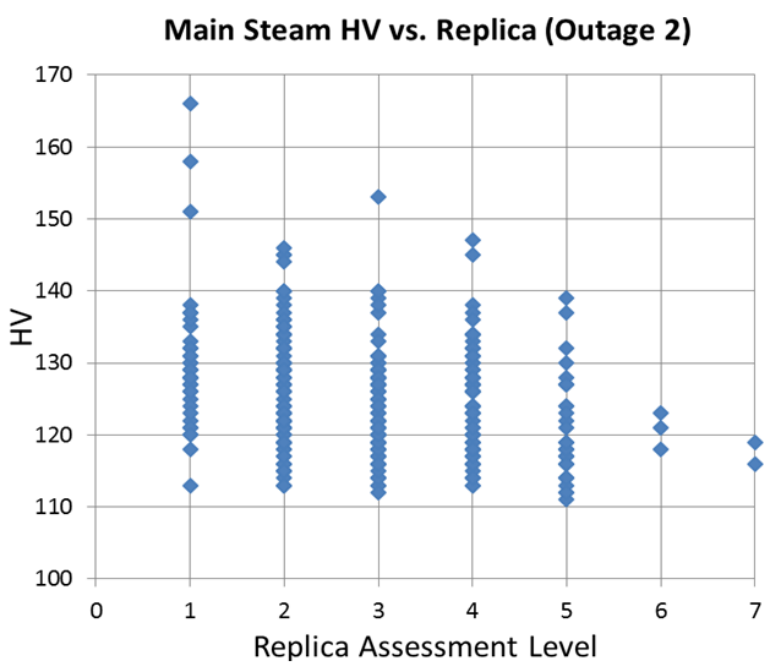

(b)

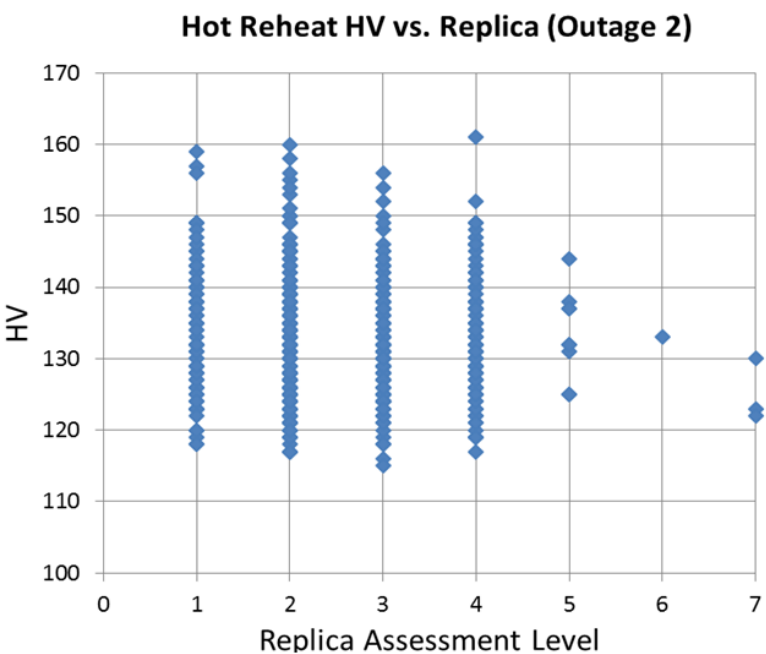

(d)

Figure 3. Hardness vs. Creep Replica Assessment Level for (a) Outages 1 and (b) Outages 2; hardness range for Hot Reheat pipework for (c) Outages 1 and (d) Outages 2.

The pipe sections are suspended in a hanger system and it is evident from periodic weld inspections that the effects of the what is termed 'pipe system stress' can manifest itself as areas of creep damage (by surface replica) in localised regions of a weld. The magnitude of active pipe system stress can be estimated by conducting hot and cold pipe hanger support surveys and recalculation of the deformed pipe shape. One of the problems with this is that over time as inspections progress invariably pipe spools for are inserted for repair purposes and the original set pipe system 'cold pull' is invariably adjusted; which forces the operator once again to fall back on to a process of management by sample inspection (typically based around key weld locations). 
It can be seen that the application of a representative hardness based stress model, that could account for the loading applied to an operational steam line and importantly be amenable for update, by use of small specimen sampling [1] and other data such as obtained from pipe hanger adjustments and operational steam temperatures and pressures would be advantageous.

\subsection{Application of Data in Life Assessment}

In addition to the physical inspections described in the case study, periodic assessments of operating temperatures are undertaken as well to determine the creep effective temperature [1]. This provides a reference operating temperature, which is subsequently compared against the design specification, which may of course subsequently prompt adjustments to the boiler operating parameters. This creep effective operating temperature assessment however does not take into account the specific material condition and creep response under load, nor does it take into account the imposed loading as result of how the pipe system is supported and adjusted throughout its operational life.

So, when faced with this type of data and findings from periodic outage inspections a number of approaches are considered as the asset approaches end of life. The benefits and challenges associated with these options are outlined in Table 5.

Table 5. End of life options.

\begin{tabular}{|c|c|c|}
\hline Options & Benefits & Challenges \\
\hline $\begin{array}{c}\text { Run } \\
\text { replacement } \\
\text { schemes planned) }\end{array}$ & Low capital investment & $\begin{array}{r}\text { Incur significant increase in outage scope and } \\
\text { cost as the plant ages if the operational risk is } \\
\text { to be adequately managed. }\end{array}$ \\
\hline Repair & $\begin{array}{c}\text { Remove perceived higher } \\
\text { risk components }\end{array}$ & $\begin{array}{c}\text { Conducting repairs on ageing materials may } \\
\text { not be straightforward and will invariably } \\
\text { require additional inspection and condition } \\
\text { Replace }\end{array}$ \\
$\begin{array}{c}\text { Replace and effectively } \\
\text { eliminate the risk }\end{array}$ & Very significant costs involved \\
\hline
\end{tabular}

In the safety case scenario described in Section 4.1 the decision was made to replace the complete pipework system, but on the premise that the station had a relatively long remaining life and the market revenue outlook was healthy. Subsequent to this decision, another unit of 
similar age was faced with the same considerations 12 months later. However, in this case the market conditions had changed significantly, with much lower revenue projections and earlier station closure date. It is no surprise that for this unit the full pipework replacement was deferred and only limited (higher risk) sections of pipework were subsequently replaced. Operation of this unit until station closure will incur increased outage inspection and condition monitoring.

\subsection{Risk Management}

Ongoing risk management is heavily reliant on a proactive response to the findings from statutory outage inspections. Ideally and arising problems are dealt with (repaired or replaced) during the outage, hence reducing the risk over the next operational period. However, this is not a cost effective approach and it is notable that as the plant ages there is a very significant increase in the scope and cost of site inspections during an outage. The case study in Section 4.1 on parent CMV material represents only a small proportion of the inspections that occur on a unit's pressure systems.

Because of the potentially serious consequences arising from the failure of a high temperature pressure system, all operating stations take a cautious approach and will, in the absence of more quantitative assessment methods, continue to implement the repair-replace options discussed earlier. This approach is commercially tolerable if the revenues are healthy, however recent market forces in the UK has significantly reduced available revenues and stations are having to reassess operating risks and seek opportunities that can reduce the remaining life cost, whilst maintaining adequate risk management.

It is useful to put the current inspection and assessment approach into context. Figure 4 illustrates the increase in the volume of outage metallurgical inspections that arise as a plant approaches its end of life, denoted by ' $t$ ' in Figure 4 . The preceeding statutory outages are specified at points ' $t-1$ ', ' $t-2$ ' etc, and each of these operating periods are typically of 4 year duration, equating to circa 20,000 hours operation. The end of life outage ' $t$ ' represents the position outlined in the case study outage 2 . It is not inconceivable to consider a $t+1$ period of heavily monitored life extension whereby the increase in site metallurgical inspections would significantly exceed the endpoint illustrated in Figure 4. 


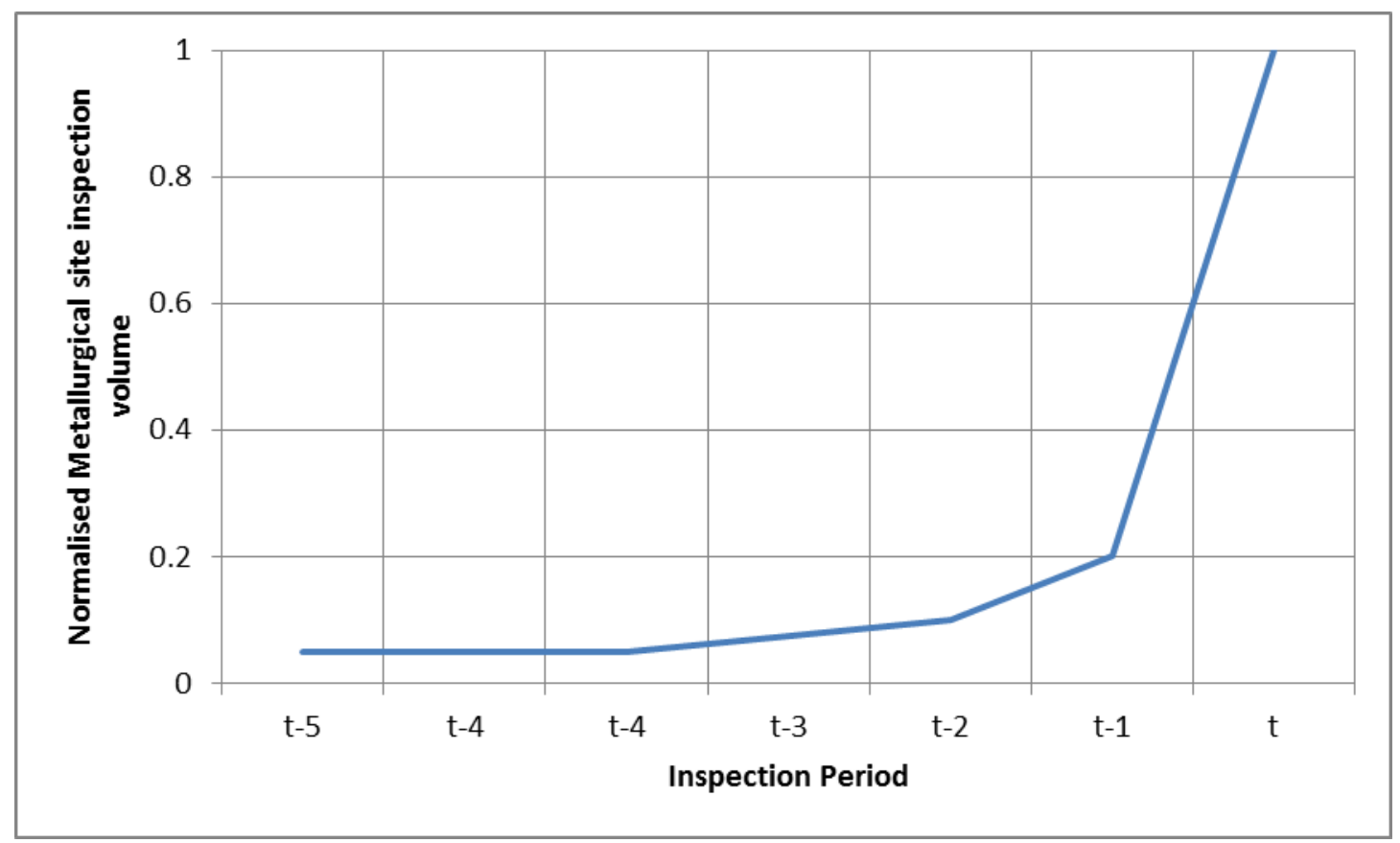

Figure 4. Normalised metallurgical inspection volume against outage period.

From a risk management perspective there is currently a heavy reliance on the intelligence gathered from such invasive metallurgical inspections. Figure 5 provides an overview of how this manifests itself in terms of decision making and informing the asset owner on risk and mitigation options. 


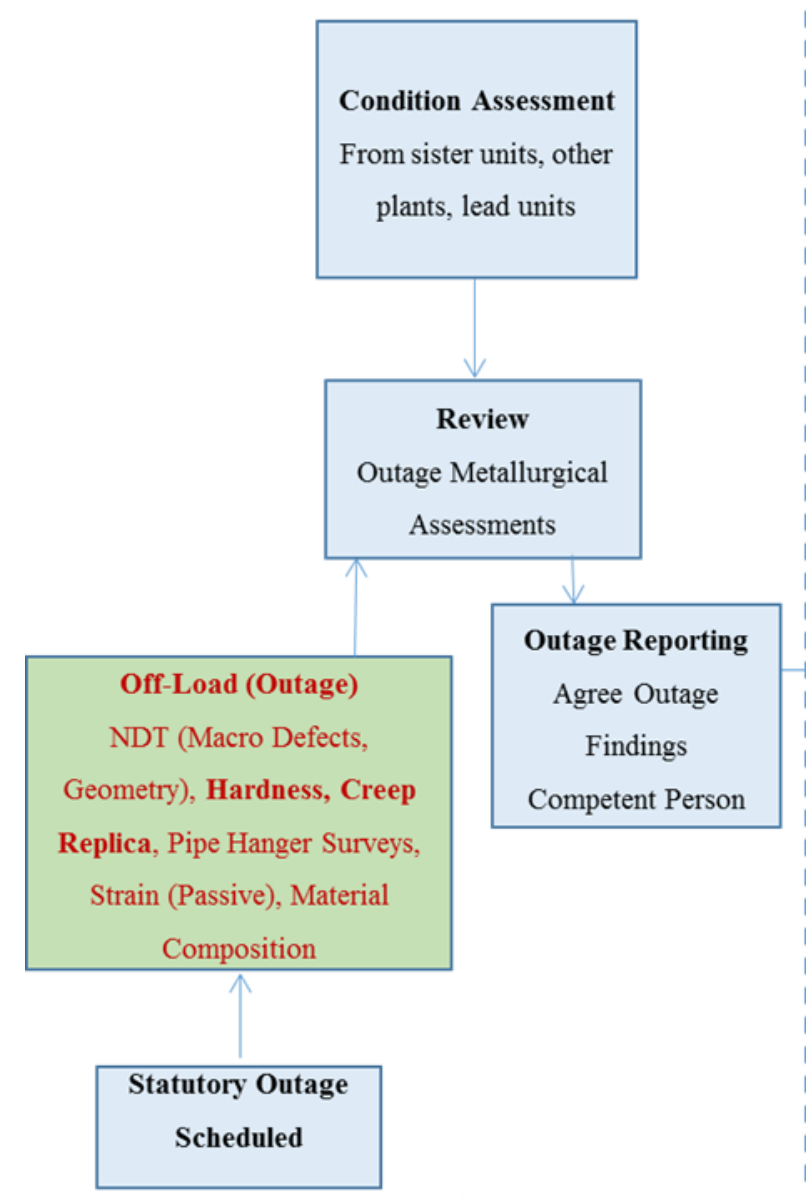

Outage

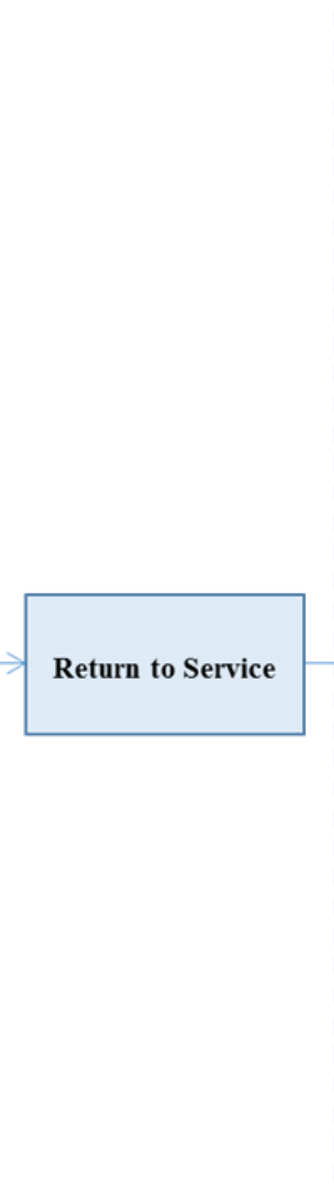

Transition
Business Perspective

Risk Appetite

Regulations

Market Conditions

Revision, Informs

Operational Duty

Inspection Planning

Plant Replacement, Repair

Strategy

Business as usual

Figure 5. Current risk management process.

A framework for applying high temperature plant condition assessment is provided in Figure 14 of [1], which shows a schematic of the current integrity management approach. In particular it emphasizes the need to correlate the data acquired during off-load monitoring, such as hardness, with creep data, obtained, for instance, by use of miniature creep test specimens, in order to develop a more proactive method for life management [1]. The important point to note is there is an opportunity to deploy targeted hardness testing, supported by an improved life assessment model as described in this paper. It is useful to reflect on the graphical illustration in Figure 4, which is based on current practice and the significant increase in the extent of invasive inspections as a plant ages in service.

It is unlikely that this commercial pressure will ease for conventional thermal plant, especially when the increasing availability of renewables generation is considered. Hence, maintaining the status quo with regard to the scope of outage inspections is not really commercially viable. This is prompting the development of a number of innovative 
approaches bas part of the sponsoring Flex-E-Plant consortium, such as the use of small specimen testing and online monitoring as part of a new approach to life management [1]. This paper outlines the potential for more proactive use of hardness data routinely acquired during outage overhauls in a predictive creep life model, as outlined in the following Section.

\section{Novel Empirical Relations between Hardness and Minimum Creep Strain Rate}

\subsection{The Relationship between Hardness and Minimum Creep Strain Rate}

Creep life is a function of the operating temperature and stress, while hardness change, after prolonged service, is mostly related to the thermal aging at the operating temperature [39]. Although creep and hardness data are not correlated by any mathematical model because of the different parameters they are related to, which represent different deformation mechanism [39], it is possible to find a fitting equation that relates the minimum creep strain rate (MSR), $\dot{\varepsilon}_{\text {min }}^{c}$, to hardness. Figure 6 shows minimum creep strain rate obtained by impression creep and uniaxial creep tests plotted against Vickers hardness at room temperature at $600^{\circ} \mathrm{C}$ at a reference stress of 155MPa, for Grade P91 steels with different service histories.

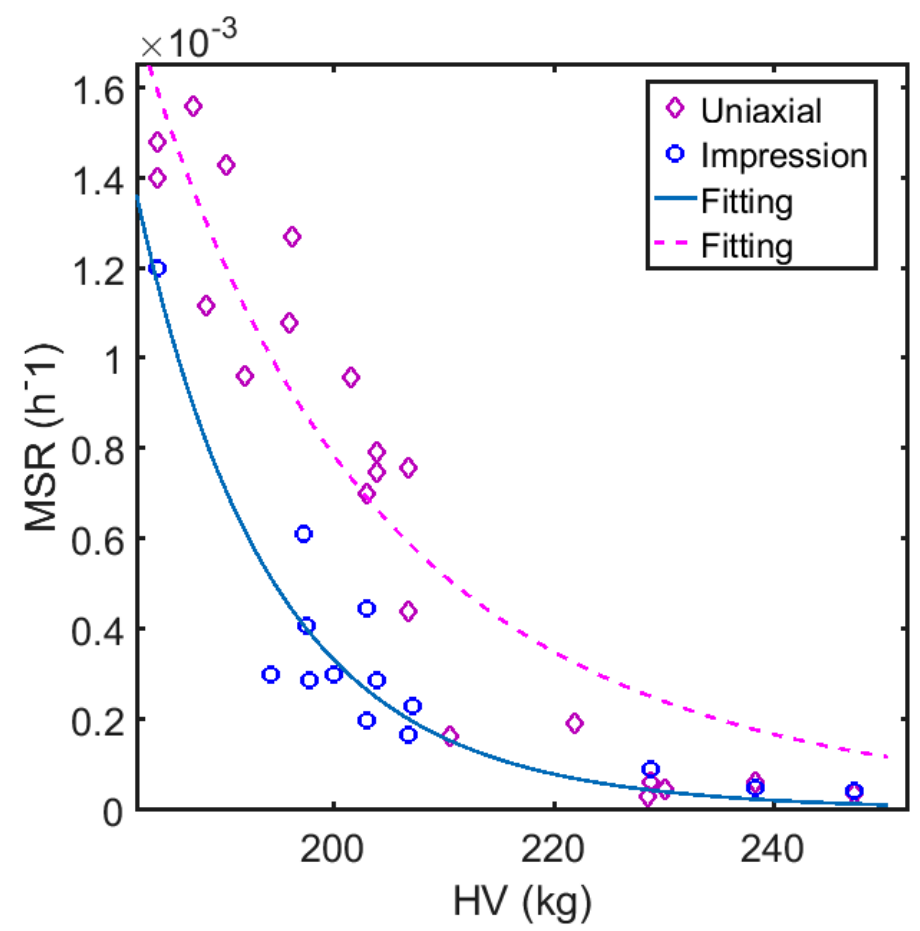

Figure 6. Minimum creep strain rate obtained by impression creep and uniaxial creep tests versus Vickers Hardness at room temperature at $600^{\circ} \mathrm{C}$ at a reference stress of $155 \mathrm{MPa}$, for Grade P91 steels with different service histories.

The phenomenological relationship between MSR and hardness is given in equation (15), where $a$ and $b$ are fitting constants, listed in Table 6. 
$\dot{\varepsilon}_{\min }^{c}=a H V^{b}$

Table 6. Fitting constants for equation (15) (for $\dot{\boldsymbol{\varepsilon}}_{\min }^{c}$ in $\mathrm{h}^{-1}$ ).

\begin{tabular}{|c|c|c|}
\hline Creep Test & $\mathbf{a}$ & $\mathbf{b}$ \\
\hline Uniaxial & $2.34 \times 10^{16}$ & -8.463 \\
\hline Impression & $1.75 \times 10^{23}$ & -11.53 \\
\hline
\end{tabular}

For ductile materials, the relationship between MSR and stress, $\sigma$, at a given temperature is generally expressed by Norton's power-law, here given in equation (16) under uniaxial conditions, where $n$ and $B$ are material constants depending on the test temperature and are listed in Table 7. By substituting the second term of equation (15) in equation (16), a relationship between Vickers hardness and stress, can be obtained as in equations (17) and (18).

$\dot{\varepsilon}_{\min }^{c}=B \sigma^{n}$

$H V=\left(\frac{B}{a} \sigma^{n}\right)^{1 / b}$

$\sigma^{n}=\left(H V^{b} \frac{a}{B}\right)^{1 / n}$

For multi-axial situation, $\sigma$ can be replaced by the equivalent stress, $\sigma_{\mathrm{EQ}}$, and $\dot{\varepsilon}_{\min }^{c}$ can be replaced by the effective strain rate.

Equation (17) has many limitations due to its phenomenological nature, but can give some information about the decrease of hardness with stress during creep exposure time, stating $b<n$. Furthermore, equation (18) can be used to relate hardness with damage, $\omega$, defined as the ratio between the damaged area and the initial area, $A_{0}$. Damage can thus be expressed by equation (19), where $A^{\prime}$ is the undamaged area.

$\omega=\frac{A_{0}-A^{\prime}}{A_{0}}$, with $0 \leq \omega \leq 1$

Cavitation damage is well described by Liu and Murakami's constitutive model, which allows the entire creep curve to be obtained and which degenerates to Norton's law when $\omega=0$ [40]. The uniaxial form of Liu and Murakami's model is given in equations (20) and (21), where $\mathrm{D}, q_{2}$ and $\chi$ are material constants, values of which, for Grade P91 at $600^{\circ} \mathrm{C}$, are collated in Table 7. The procedure to establish these constant is described later in the paper, in Section 5.2. 
$\dot{\varepsilon}^{c}=B \sigma^{n} \exp \left[\frac{2(n+1)}{\pi \sqrt{1+\frac{3}{n}}} \omega^{3 / 2}\right]$

$\dot{\omega}=D \frac{1-\exp \left[-q_{2}\right]}{q_{2}} \sigma^{\chi} \exp \left[q_{2} \omega\right]$

By substituting the second term of equation (18) in equations (20) and (21), a modified Liu and Murakami's damage model including hardness can be obtained and it is expressed by equations (22) and (23).

$\dot{\varepsilon}^{c}=a H V^{b} \exp \left[\frac{2(n+1)}{\pi \sqrt{1+\frac{3}{n}}} \omega^{3 / 2}\right]$

$\dot{\omega}=D \frac{1-\exp \left[-q_{2}\right]}{q_{2}}\left(H V^{b} \frac{a}{B}\right)^{\chi / n} \exp \left[q_{2} \omega\right]$

If all of the constants involved are known, damage calculation is possible by placing in equations (22) and (23) the hardness value measured at room temperature during inspections of the components, every two or four years according to the system safety regulations. The component failure can be assumed to happen when $\omega$ approaches its maximum value, 1. Although caution is necessary in using the modified Liu and Murakami creep damage model, since further investigation is needed, this novel approach could give an indication about material remaining life. In fact, although the applied stress could remain constant during service, the component hardness generally drops due to aging. Through the modified Liu and Murakami creep damage model, such drop in the hardness value will result in a reduction of the time to failure, giving the utility some useful information about the current component conditions. Test data presented in Figure 6 show that the minimum creep strain rate (MSR) increases with decreasing hardness. Under a constant loading or stress state for a given component, MSR at a position of interest is constant with time by mathematical definition, but in reality, for steel alloys currently used for power plant applications, it is not [37, 41, 42]. Therefore, a change in hardness during service history (decreasing hardness), means an increase in MSR and therefore a decrease in time to failure, meaning that the component may need to be repaired or replaced. Equations (22) and (23) can be used for monitoring because they take in input the current hardness value and give in output the current creep strain and time to failure.

Figure 7 shows the variation with time of the creep strain for the same material and 
temperature obtained by using Liu and Murakami's method with a reference stress of $155 \mathrm{MPa}$ and by using the modified Liu and Murakami method with different hardness values and fitting constants from both uniaxial and impression creep test data. For the same hardness value, equation (18) used with $a$ and $b$ from uniaxial creep test data overestimates the value of the reference stress with respect to equation (18) used with $a$ and $b$ from impression creep test data. Consequently, the value of the time to failure obtained through the modified Liu and Murakami method is overestimated.

Table 7. Constants of Liu and Murakami's damage model for a Grade P91 steel at $600^{\circ} \mathrm{C}$ (for $\sigma$ in $\mathrm{MPa}$ and $t$ in hrs) from ref. [43].

\begin{tabular}{ccccc}
\hline $\boldsymbol{B}$ & $\boldsymbol{n}$ & $\boldsymbol{D}$ & $\boldsymbol{\chi}$ & $\boldsymbol{q}_{2}$ \\
\hline $1.51 \times 10^{-30}$ & 11.795 & $2.12 \times 10^{-27}$ & 10.953 & 5.3 \\
\hline
\end{tabular}

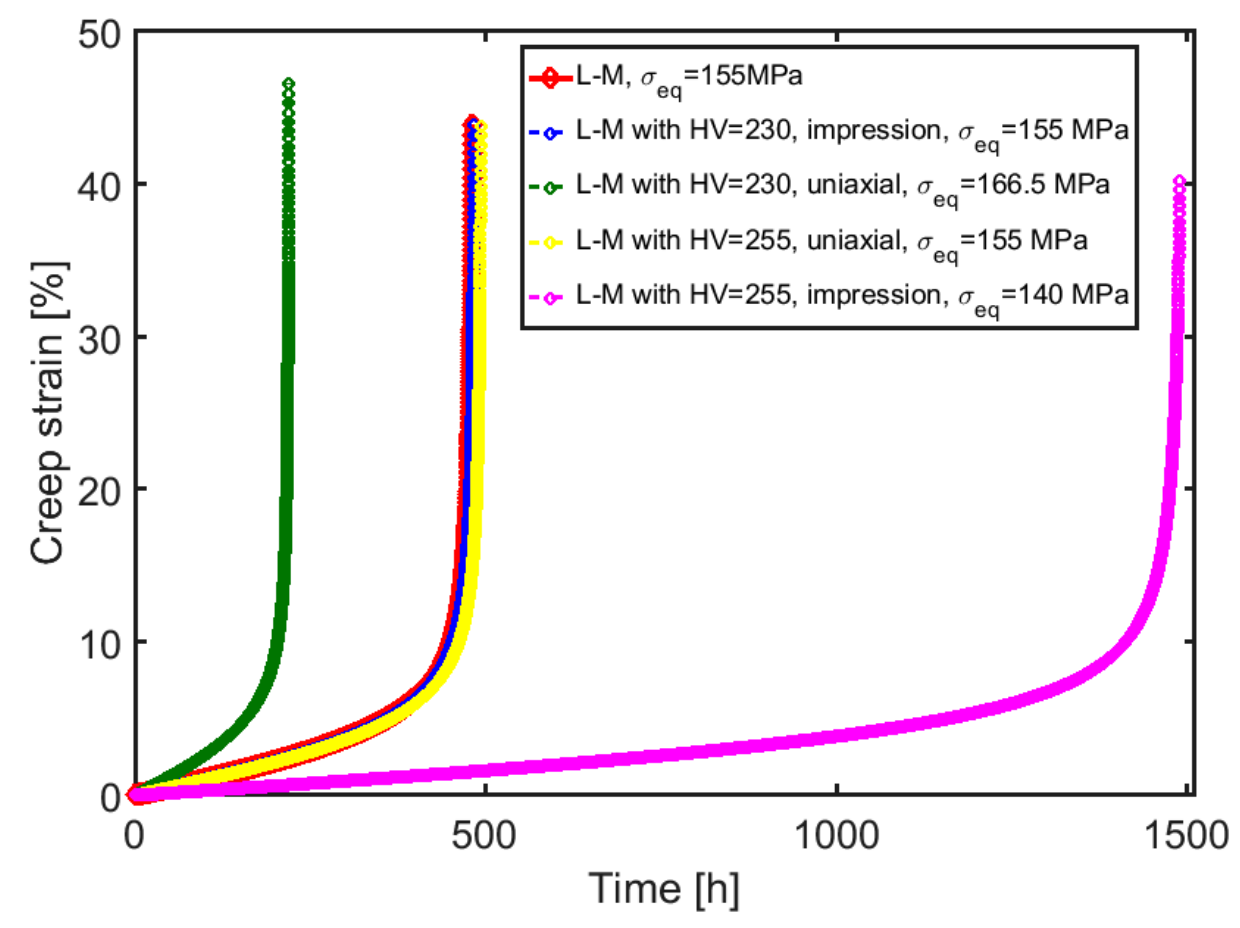

Figure 7. Creep strain versus time by using Liu and Murakami’s and the modified Liu and Murakami methods.

An estimation of the failure life from impression creep test data is also possible via the Monkman-Grant relationship, equation (24), where $m$ and $C$ are material constants [44]. By substituting $\dot{\varepsilon}^{c}$ with the second term of equation (15) in equation (24), a relationship between hardness and the failure life is obtained and expressed in equation (25). Because of the less number of material constants involved in the calculation, this method for assessing the remaining life is convenient for practical use by the plant. Furthermore, the constant $C$ can be determined by only one uniaxial test, and, for ferritic steels, $m$ is roughly equal to 1 . 
Monkman-Grant's relationship is intended as only a guide for remaining life assessment [44] as well as equation (25).

$$
\begin{aligned}
& \log \left(t_{r}\right)+m \log \left(\dot{\varepsilon}^{c}\right)=C \\
& \log \left(t_{r}\right)+m \log \left(a H V^{b}\right)=C
\end{aligned}
$$

However, when HV > 190, the modified Liu and Murakami model is generally able to provide failure time from impression creep test results closer to the corresponding uniaxial creep test data than Monkman-Grant's relationship (equation (24)), as shown in Figure 8, which presents the variation of the time to failure with hardness value. It is worth to note that the proposed method does not need an initial hardness value at $t=0 \mathrm{hrs}$ for the failure life to be established, contrary to other approaches established so far [16, 28, 32-34] and described in Section 3.

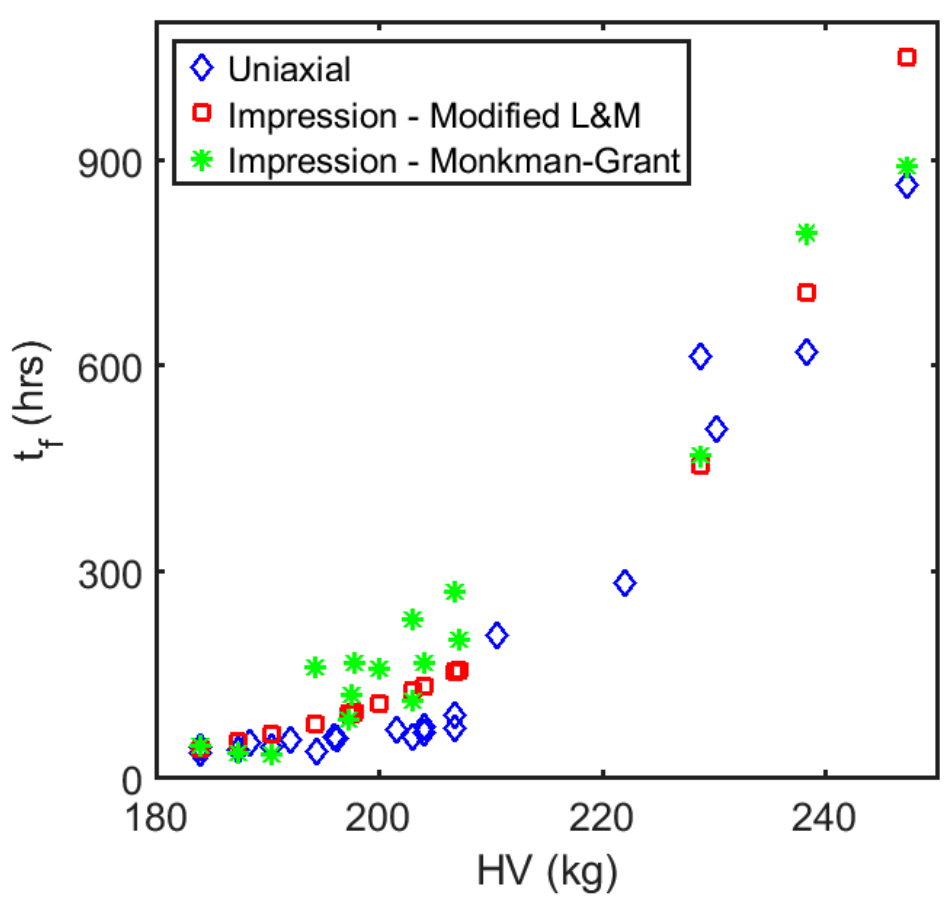

Figure 8. Variation of the time to failure with hardness for a Grade P91 steel at $600^{\circ} \mathrm{C}$ and $155 \mathrm{MPa}$, obtained by uniaxial, impression creep with modified Liu and Murakami's method, and impression creep with Monkman-Grant's relationship.

\subsection{Determination of the Material Constants}

Liu and Murakami's damage model can be implemented in ABAQUS through the use of a CREEP User Subroutine [45].

The determination of Liu and Murakami's damage model material constants is well described in [46] and it is here reported only for the reader's convenience. 
In order to determine these material constants, at least three uniaxial creep tests have to be carried out at different stresses under the same temperature. By representing equation (16) in an alternative form, such as equation (26), a plot of $\log \left(\dot{\varepsilon}_{\min }^{c}\right)$ versus $\log (\sigma)$ will produce a straight line [46]. The slope of the best linear fitting is the material constant $n$, and the intercept is $\log (B)$.

$\log \left(\dot{\varepsilon}_{\min }^{c}\right)=n \log (\sigma)+\log (B)$

Similarly, the constants $D$ and $\chi$ can be determined from the same tests by plotting $\log \left(t_{r}\right)$ versus $\log (\sigma)$, equation (27), that will produce a straight line; $\chi$ and $\mathrm{D}$ values can be obtained from the slope and the intercept, respectively [46].

$\log \left(t_{r}\right)=-\chi \log (\sigma)+\log \left(\frac{1}{D}\right)$

In order to determine the material constant $q_{2}$, a curve of creep strain, $\varepsilon^{c}$, versus $t$, such that given in equation (28), must be obtained for each stress level [46], where $e$ is the Neper number.

$$
\dot{\varepsilon}^{c}=B \sigma^{n} \exp \left[\frac{2(n+1)}{\pi \sqrt{1+\frac{3}{n}}}\left(-\frac{\ln \left(1-D\left(1-e^{-q_{2}}\right) \sigma^{\chi} t\right.}{q_{2}}\right)^{3 / 2}\right]
$$

Equation (28) does not have a close-form solution, therefore a time-marching procedure is needed and it can be carried out by calculating the creep strain increment, $\Delta \varepsilon_{i}^{c}$, at the current time step, $i$, as in equation (29), where $\Delta t$ is a small (constant) time interval and $\dot{\varepsilon}_{i}^{c}$ is the minimum creep strain rate at the current time step, $i$ [46].

$\Delta \varepsilon_{i}^{c}=\dot{\varepsilon}_{i}^{c} \cdot \Delta t$

These creep strain increments are then accumulated to give the value of the total creep strain at the $i$ time step, as showed in equation (30) [46].

$\varepsilon_{i}^{c}=\varepsilon_{i-1}^{c}+\Delta \varepsilon_{i}^{c}$

This procedure must be carried out up to time to failure, $t_{r}$, by using the initial values of $n, B$, $D$ and $\chi$ calculated so far and an initial, attempting, value of $q_{2}$; an optimization process can 
be used to obtain the material constants that give the best fit to all of the experimental $\varepsilon_{\mathrm{c}}$ versus $t$ curves [46].

The material constants for the modified damage model, $a$ and $b$, can be established as explained at the beginning of Section 5. Further research is certainly needed, but, based on engineering judgment, at least ten impression creep tests or ten uniaxial creep tests at the same temperature seem to be necessary in order to have enough data for the curve fitting (see Figure 6). If the specimens are from the same material, but have different service histories, the same reference stress for the creep tests must be used. If the material is exactly the same for all of the specimens, the creep tests must be carried out at different reference stresses. When only a small volume of material is available, the impression creep test is recommended, also because it is generally shorter than the "equivalent" uniaxial creep test. A full description and a critical review of impression creep test are discussed elsewhere [1, 47]. The recommended geometry dimensions of a rectangular impression creep test specimen are $w_{I}=b_{I} \approx 10 \mathrm{~mm}, d_{I} \approx 1 \mathrm{~mm}, h_{I} \approx 2.5 \mathrm{~mm}$ [48], where $d_{I}$ is the indenter width, $w_{I}, b_{I}$ and $h_{I}$ are the width, the length and the thickness of the sample, respectively, as shown in Figure 9 (a). A schematic diagram of specimen and loading arrangement is presented in Figure 9 (b).

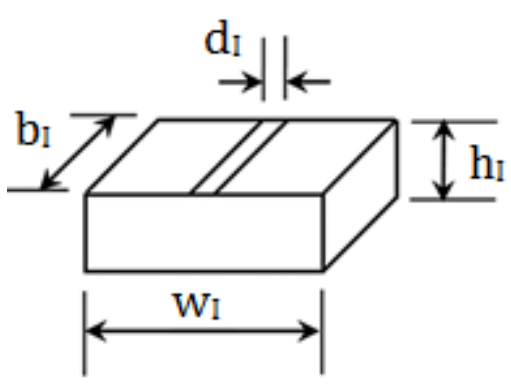

(a)

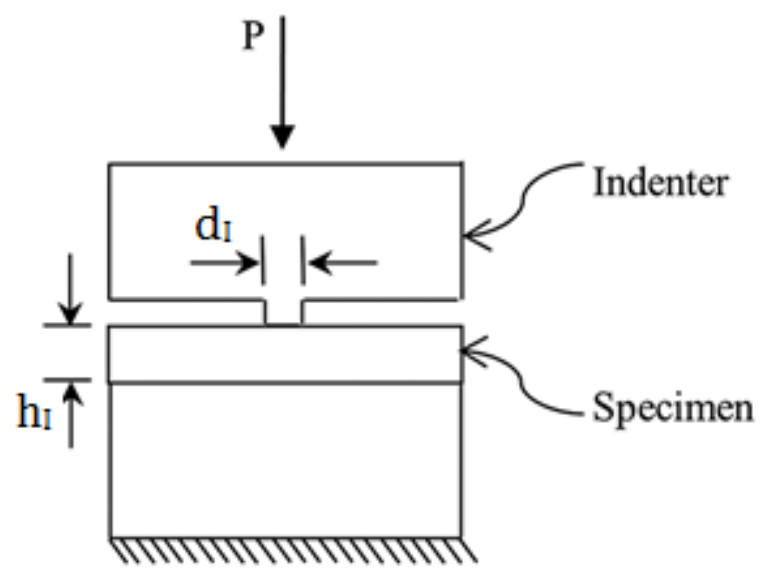

(b)

Figure 9. (a) Impression creep test specimen adapted from ref. [48] and (b) schematic diagram showing the specimen loading arrangement, adapted from ref. [49].

\subsection{Model Implementation and Validation}

Implementation and validation of the hardness modified Liu and Murakami model for inservice operational conditions would be approached with the following considerations. 
The case study on CMV hardness data acquired during periodic outage inspections in Section 4 has identified a reduction in hardness levels in service, and for this case study example over a service period of $\sim 20,000$ hrs. Over an extended period of service from initial commissioning it is feasible to consider acquiring hardness data, but with the following guidance.

- If possible secure some extra lengths of pipe during the construction phase so that parent and welded test specimens can be manufactured at a suitable time in order to quantify initial material lifing parameters. Other opportunities to acquire materials will almost certainly arise during service, for example it may be necessary to replace a defective weld or valve. Reference to the guidance in Section 5.2 on typical specimen size and quantity should be referred to.

- In the ideal case, baseline hardness measurements would be acquired during the initial construction phase of the plant. For example, this data could be acquired on selected locations at the same time as original construction welds are inspected.

- Identify a small number of reference locations on the pipe system, ideally adjacent to accessible fixed walkways and platforms to negate any requirement for installation of temporary scaffolding. For a typical main steam line on a conventional unit this could be circa 4-5 locations, one adjacent to the boiler stop valve located at the boiler outlet, one towards the high pressure stop/control valve and the remainder at intermediate positions.

- As the station enters service there will be opportunities to acquire hardness data at times other than during the main statutory outages; typically this would be during short planned maintenance outages. In this event, having accessible reference locations identified is essential in order to minimise access costs.

- Periodic statutory outages provide the ideal opportunity to acquire hardness data at targeted locations. The question then arises, how is this data subsequently used in a practical way to predict the life consumption rate and importantly advise the station on, a) any modifications to operating duty, b) optimising the inspection schedule for the next statutory outage.

- A whole pipe work system interface framework model has been developed [50] as part of the Flex-E-plant consortium. This model provides a readily available method whereby the hardness modified Liu and Murakami creep damage model discussed in this paper could be implemented. 
- Iteration is a necessary step to challenge, improve and ultimately validate the proposed damage model; this must be facilitated by scrutiny of other plant condition assessment data routinely obtained during plant outages and likely supplemented using targeted small specimen extraction and testing [1]. The available whole pipe system interface framework [50] enables the implementation of this hardness modified Liu and Murakami creep damage model described in this paper.

The above outlines an approach to model validation that is essentially based on periodic recalibration in order to optimise operation and the scope of through life plant inspections. There are many other high temperature systems and components in operation on a typical large conventional thermal power station. The general approach described above is equally applicable to these, however these may present different challenges. For example, the complex geometry encountered in steam headers and large forgings and castings requires the development of novel analytical approaches to assess the impact of operational temperature and pressure cycles via online monitoring. Examples of relevant approaches for these components are available [51].

\section{Discussion and concluding remarks}

The case study on CMV parent material has illustrated the general reduction in surface hardness as material ages under operational conditions. A correlation between the change in creep replica assessment level and surface hardness is not evident from the data set studied, moreover it is important to consider that any change in creep replica assessment level will only be identified during the later stages of operational life. Hence, this is not particularly conducive for through life condition monitoring and future life prediction. The reduction in hardness through life presents an opportunity to use this routinely measured parameter in a predictive assessment model, hence providing a proactive means of identifying adverse rates of change in hardness that may be indicative of the approach to end of life and retirement from service. Currently the hardness data acquired from a site outage is scrutinised to determine any notable and consistent trends that indicate deterioration; often in conjunction with review of surface replcas. Unfortunately, there is no routinely deployed assessment model in use to provide a more quantitative prediction of residual life. Typically, indications of consistent hardness reduction (softening) will proactively prompt repairs or component replacements. This approach is clearly sub-optimal and practical improvements can only be achieved by the development and use of a suitable predictive life model, with timely 
feedback to improve plant operation.

An approach for the implementation of surface hardness in the Liu and Murakami damage model has been illustrated. Currently the only approach in common use to predict the rate of creep life consumption is via the calculation of the creep effective temperature. However this has been shown to have several limitations [1] and can realistically only be considered to provide information complementary to that acquired during the invasive outage inspections, which increase in scope as the plant ages, as illustrated in Figure 4.

Use of routinely acquired hardness data in a model such as Liu and Murakami's gives the operator scope to assess the effect of the rate of change in hardness and predict the likely impact of this for future operation and ultimately influencing the scope of future outage inspections.

Practical assessment tools have been developed as part of the Flex-E-Plant consortium [50] that allow the rapid definition of whole pipe system models, which permit the input of pipe support hanger loads, operational conditions and user defined creep damage models such as the modified Liu and Murakami model described in this paper. This for the first time allows the station to proactively use this routinely acquired data to determine the current rate of damage accumulation and importantly predict the future rate of damage accumulation. Clearly, as the comparison of the site outage hardness and creep replica results has shown, there is a need to validate any subsequent prediction of life consumption. This is necessarily an iterative process, but one which will not be implemented unless suitable and cost-effective assessment tools are available. Section 5.3 describes an iterative approach to plant assessment that will guide validation of the model proposed in this paper and for that matter any other similarly defined lifing model. Importantly there is now an assessment tool [50] that enables these pipe models to be effectively implemented, within a site operational context. The case study presented has alluded to more restrictive electricity markets for conventional thermal power plants; this in itself should drive the implementation of these novel predictive life assessment approaches that importantly take advantage of site information currently acquired and enabled by the efficient use of novel computational models.

\section{Acknowledgments}

This work is supported by the Engineering and Physical Sciences Research Council (Grant number: EP/K021095/1). 
We would like to thank the Flex-E-Plant partners for their the valuable contributions: GE Power, Doosan Babcock Limited, Centrica plc., EDF Energy (West Burton Power) Limited, E.ON Technologies (Ratcliffe) Limited, Goodwin Steel Castings Limited, NPL Management Limited, R-MC Power Recovery Limited, RWE Generation UK plc., Scottish and Southern Energy (SSE) plc., Siemens Industrial Turbomachinery and TWI Limited. The authors would like to acknowledge members of the Flex-E-Plant consortium and EDF Energy for permission to publish this paper. 


\section{References}

1. Morris, A., B. Cacciapuoti, and W. Sun, The Role of Small Specimen Creep Testing within a Life Assessment Framework for High Temperature Power Plant. International Materials Reviews, 2018. 63(2): p. 102-137.

2. Tabor, D., The hardness of solids. Review of Physics in Technology, 1970. 1(3): p. 145.

3. Vander Voort, G.F. and G.M. Lucas, Microindentetion Hardness testing. Advanced Materials and Processes, 2000. 9/98: p. 21-25.

4. Song, J.-F., S. Low, D. Pitchure, A. Germak, S. DeSogus, T. Polzin, H.-Q. Yang, and H. Ishida, Establishing a worldwide unified Rockwell hardness scale using standard diamond indenters. Measurement, 1998. 24(4): p. 197-205.

5. Hill, R., The mathematical theory of plasticity. 1950, Oxford: Clarendon Press.

6. Tabor, D., The hardness of metals. 1951, Oxford: Clarendon Press.

7. Tresca, M.H., On further applications of the flow of solids. Journal of the Franklin Institute, 1878. 106(4): p. 263-270.

8. Pavlina, E. and C. Van Tyne, Correlation of yield strength and tensile strength with hardness for steels. Journal of Materials Engineering and Performance, 2008. 17(6): p. 888-893.

9. Shaw, M.C. and G.J. DeSalvo, A new approach to plasticity and its application to blunt two dimensional indenters. Journal of Engineering for Industry, 1970. 92(2): p. 469-479.

10. Shaw, M.C. and G.J. DeSalvo, The role of elasticity in hardness testing. Met. Eng. Quart., 1972. 12: p. 1-7.

11. Westbrook, J.H., The science of hardness testing and its research applications. 1973.

12. Cahoon, J., An Improved Equation Relating Hardness to Ultimate Strength. Metallurgical and Materials Transactions B, 1972. 3: p. 3040.

13. Cahoon, J., W. Broughton, and A. Kutzak, The determination of yield strength from hardness measurements. Metallurgical and Materials Transactions B, 1971. 2(7): p. 1979-1983.

14. Hsu, C.-y., Correlation of hot-microhardness with elevated-temperature tensile properties of low activation ferritic steel. Journal of Nuclear Materials, 1986. 141: p. 518-522.

15. Gooch, D.J., Creep and high-temperature failure, in Comprehensive structural integrity (ed. I. Milne et al.), A. Saxena, Editor. 2003, Elsevier: Amsterdam. p. 309359.

16. Masuyama, F., Creep degradation in welds of Mod.9Cr-1Mo steel. International Journal of Pressure Vessels and Piping, 2006. 83(11-12): p. 819-825.

17. Sposito, G., C. Ward, P. Cawley, P.B. Nagy, and C. Scruby, A Review of NonDestructive Techniques for the Detection of Creep Damage in Power Plant Steels. NDT \& E International, 2010. 43(7): p. 555-567. 
18. Viswanathan, R., S.R. Paterson, H. Grunloh, and S. Gehl, Life assessment of superheater reheater tubes in fossil boilers. Journal of Pressure Vessel Technology, Transactions of the ASME, 1994. 116(1): p. 1-16.

19. Parker, J., In-service behavior of creep strength enhanced ferritic steels Grade 91 and Grade 92 - Part 1 parent metal. International Journal of Pressure Vessels and Piping, 2013. 101: p. 30-36.

20. The Use of Portable Hardness Testing in Field Applications for Grade 91 Steel. EPRI, Palo Alto, CA (2011) 1023199, 2012.

21. Guidelines and specifications for high-reliability fossil power plants: best practice guideline for manufacturing and construction of Grade 91 steel components. EPRI, Palo Alto, CA (2011) 1023199, 2015.

22. An Informed Perspective on the Use of Hardness Testing in an Integrated Approach to the Life Management of Grade 91 Steel Components. EPRI, Palo Alto, CA (2011) $1023199,2016$.

23. Infante, V., J.M. Silva, M. de Freitas, and L. Reis, Failures analysis of compressor blades of aeroengines due to service. Engineering Failure Analysis, 2009. 16(4): p. 1118-1125.

24. Hollomon, J.H. and L.D. Jaffee, Time-temperature relations in tempering steel. Trans. AIME, 1943. 162: p. 223-249.

25. Kohlhofer, W. and R.K. Penny, Hardness testing as a means for creep assessment. International Journal of Pressure Vessels and Piping, 1996. 66(1-3): p. 333-339.

26. Cane, B.J., P.F. Aplin, and J.M. Brear, A Mechanistic Approach to Remanent Creep Life Assessment of Low Alloy Ferritic Components Based on Hardness Measurements. Journal of Pressure Vessel Technology. Transactions of the ASME, 1985. 107(3): p. 295-300.

27. Kachanov, L.M., The Theory of Creep. 1958: Kennedy A.J. (ed., English Translation), National Lending Library, Boston, Spa.

28. Masuyama, F., Hardness model for creep-life assessment of high-strength martensitic steels. Materials Science and Engineering: A, 2009. 510-511: p. 154-157.

29. Larson, F.R. and J. Miller, A time-temperature relationship for rupture and creep stress. Transactions ASME, 1952. 74(5): p. 765-775.

30. Ghassemi Armaki, H., R. Chen, S. Kano, K. Maruyama, Y. Hasegawa, and M. Igarashi, Microstructural degradation mechanisms during creep in strength enhanced high $\mathrm{Cr}$ ferritic steels and their evaluation by hardness measurement. Journal of Nuclear Materials, 2011. 416(3): p. 273-279.

31. Mukhopadhyay, S.K., H. Roy, and A. Roy, Development of hardness-based model for remaining life assessment of thermally loaded components. International Journal of Pressure Vessels and Piping, 2009. 86(4): p. 246-251.

32. Furtado, H.C., B.R. Cardoso, F. Santos, C. Matt, and L.H. de Almeida, Remaining Life Evaluation of Power Plant Based on Strain Deformation Monitoring and Computational Diagnosis, in The 12th International Conference of the Slovenian Society for Non-Destructive Testing: Application of Contemporary Non-Destructive Testing in Engineering. September 4-6, 2013: Portorož, Slovenia. 
33. Furtado, H.C., L.H. de Almeida, J. Dille, and I. Le May, Correlation Between Hardness Measurements and Remaining Life Prediction for 2.25Cr-1Mo Steel Used in Power Plants. Journal of Materials Engineering and Performance, 2010. 19(4): p. 558-561.

34. Furtado, H.C., L.H. de Almeida, and I. Le May, Damage and Remaining Life Estimation in High Temperature Plant with Variable Operating Conditions. OMMI, Power Plant, 2008. 5: p. 1-10.

35. Allen, D.J. and S.T. Fenton, A hardness-based creep rupture model for new and service aged P91 steel, in VTT Symposium. 2007, VTT; 1999. p. 156-170.

36. Morris, A., Confidential information from EDF Energy (West Burton Power) Limited.

37. Cacciapuoti, B., The Role of Miniature Specimen Creep Tests in Power Plant Life Management. PhD Thesis, The University of Nottingham, 2018.

38. Cacciapuoti, B., A. Morris, W. Sun, D.G. McCartney, and J. Hulance, Correlation and Capability of using Site Inspection Data and Small Specimen Creep Testing for a Service-Exposed CrMoV Pipe Section. Materials at High Temperatures. Under revision., 2017.

39. Sun, W., T.H. Hyde, and S.J. Brett, Application of Impression Creep Data in Life Assessment of Power Plant Materials at High Temperatures. Proc. Instn Mech Engrs, Journal of Materials: Design and Applications, 2008. 222(Part L): p. 175-182.

40. Liu, Y. and S. Murakami, Damage Localization of Conventional Creep Damage Models and Proposition of a New Model for Creep Damage Analysis. JSME International Journal Series A, 1998. 41(1): p. 57-65.

41. Abe, F., T.-U. Kern, and R. Viswanathan, Creep-resistant steels. 2008: Elsevier.

42. Sklenička, V. and L. Kloc, 5 - Creep in boiler materials: mechanisms, measurement and modelling A2 - Oakey, John E, in Power Plant Life Management and Performance Improvement. 2011, Woodhead Publishing. p. 180-221.

43. Cortellino, F., R. Chen, W. Sun, and T.H. Hyde, A Microscopic Investigation on the Failure Mechanisms of Small Punch Creep Test of a P91 Steel at $873 \mathrm{~K}$, in SSTT Determination of mechanical properties of materials by small punch and other miniature testing techniques K. Matocha, R. Hurst, and W. Sun, Editors. 2014, OCELOT s.r.o.: Castle Seggau - Graz (Austria). p. 260-269.

44. Monkman, F.C. and N.J. Grant, An Empirical Relationship Between Rupture Life and Minimum Creep Rate in Creep-Rupture Tests. Proc. ASTM, 1956. 56: p. 593-605.

45. Cortellino, F., Experimental and Numerical Investigation of Small Punch Creep Test. 2015, Ph. D Thesis, The Univeristy of Nottingham.

46. Hyde, T.H., W. Sun, and C.J. Hyde, Applied Creep Mechanics. 2013: McGraw-Hill Professional.

47. Cacciapuoti, B., W. Sun, D.G. McCartney, A. Morris, S. Lockyer, N.A. Razak, C.M. Davies, and J. Hulance, An Evaluation of the Capability of Data Conversion of Impression Creep Test. Materials at High Temperatures, 2017. 34(5-6): p. 415-424.

48. Sun, W., T.H. Hyde, and S.J. Brett, Small Specimen Creep Testing and Application for Power Plant Component Remainig Life Assessment, in IRF2013 - 4th International Conference on Integrity, Reliability and Failure. 2013: Funchal, Portugal. 
49. Hyde, T.H., B.S.M. Ali, and W. Sun, On the Determination of Material Creep Constants Using Miniature Creep Test Specimens. Journal of Engineering Materials and Technology, 2014. 136: p. 021006-021001-021010.

50. Kapadia, P. Assessment of System Stresses and Creep-Fatigue Damage on Power Plant Pipelines using a Pipeline Modelling Tool. in International Conference HIDA7: Life/Defect Assessment \& Failures in High Temperature Industrial Structures 15 17 May 2017. Portsmouth, UK.

51. Rouse, J.P. and C.J. Hyde, A comparison of simple methods to incorporate material temperature dependency in the Green's function method for estimating transient thermal stresses in thick-walled power plant components. Materials, 2016. 9(1): p. 26. 


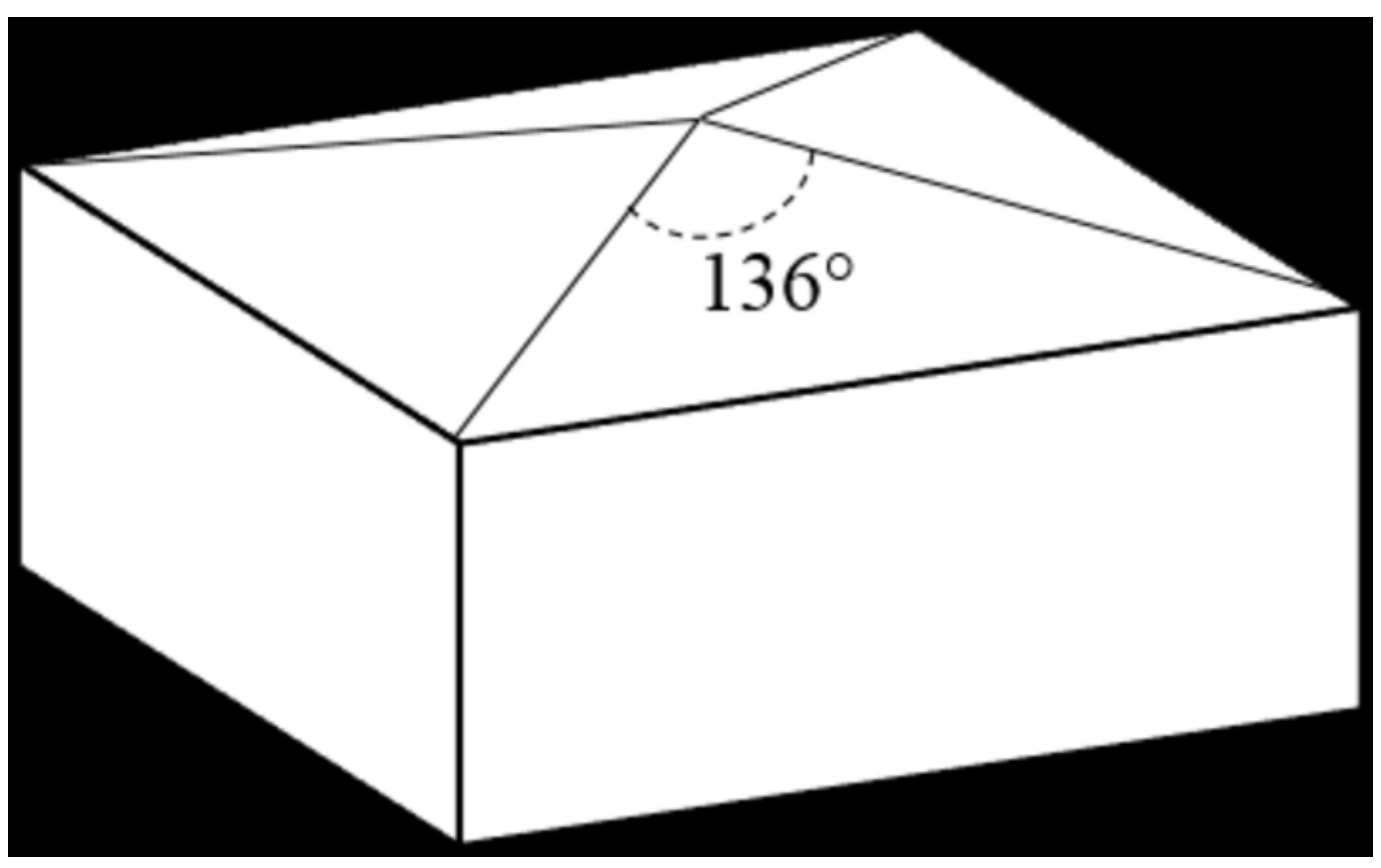

click here to download high resolution image 


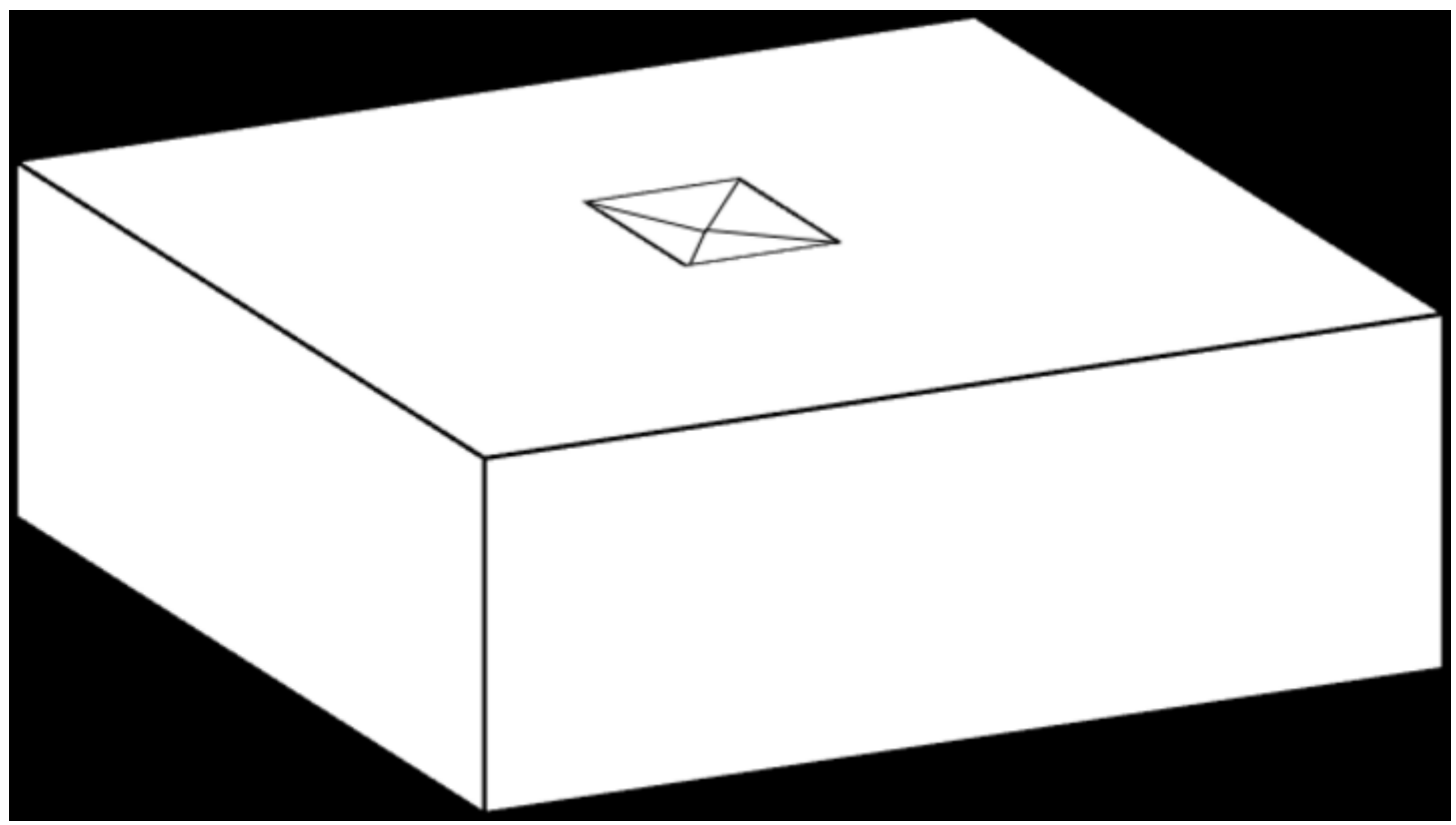




\section{Click here to download high resolution image}

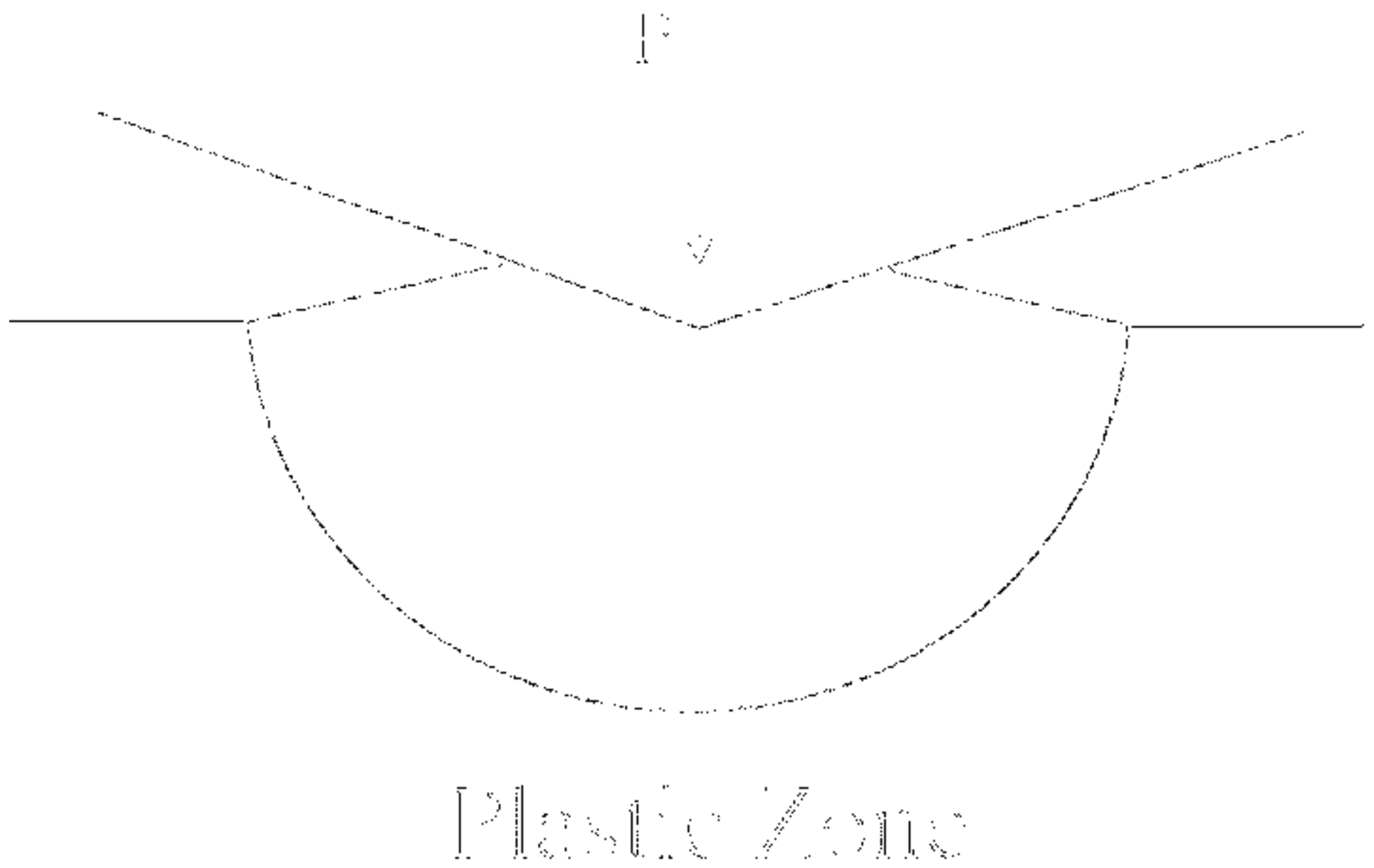




\section{Main Steam - Outage 1}

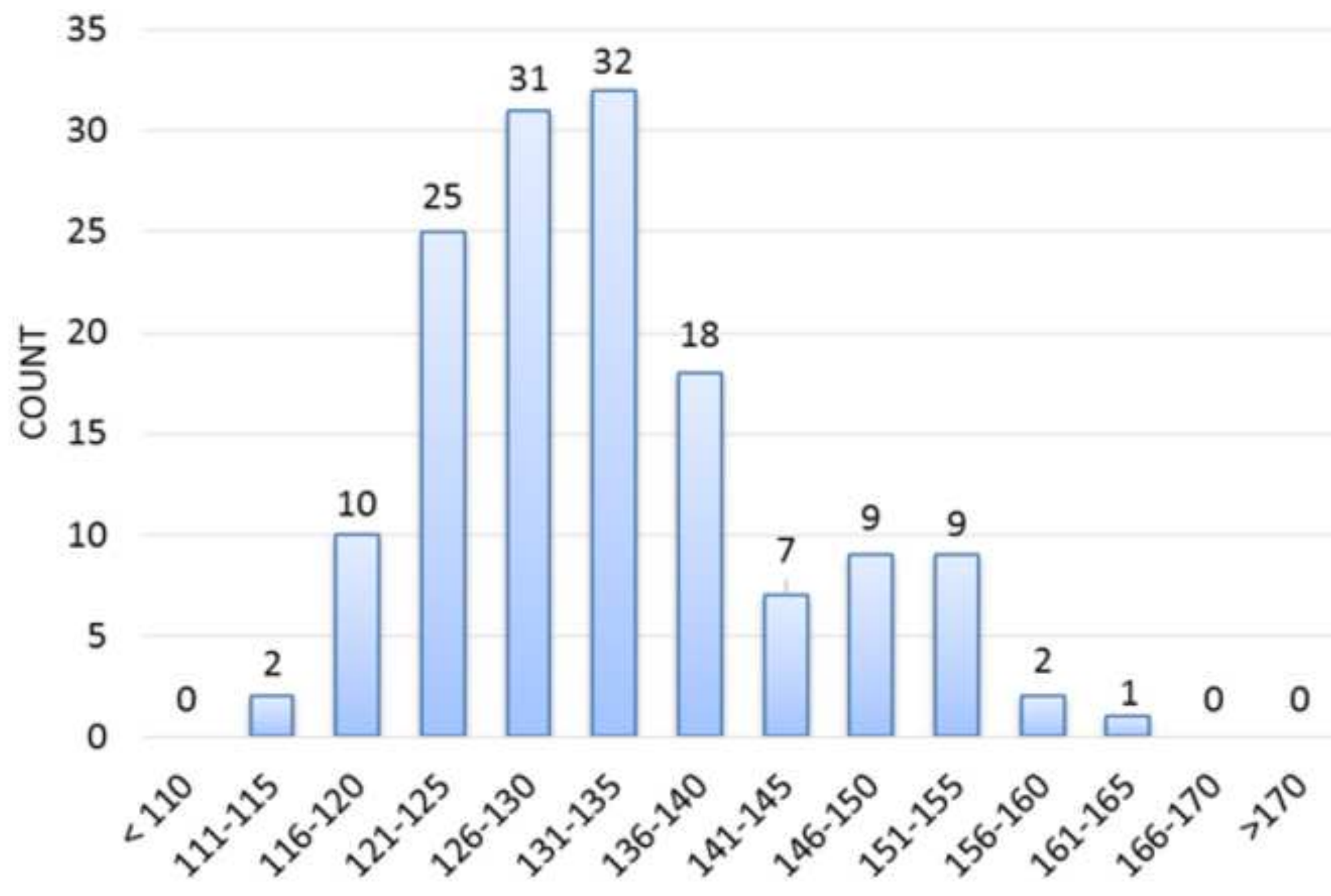

HARDNESS RANGE 


\section{Main Steam - Outage 2}

140

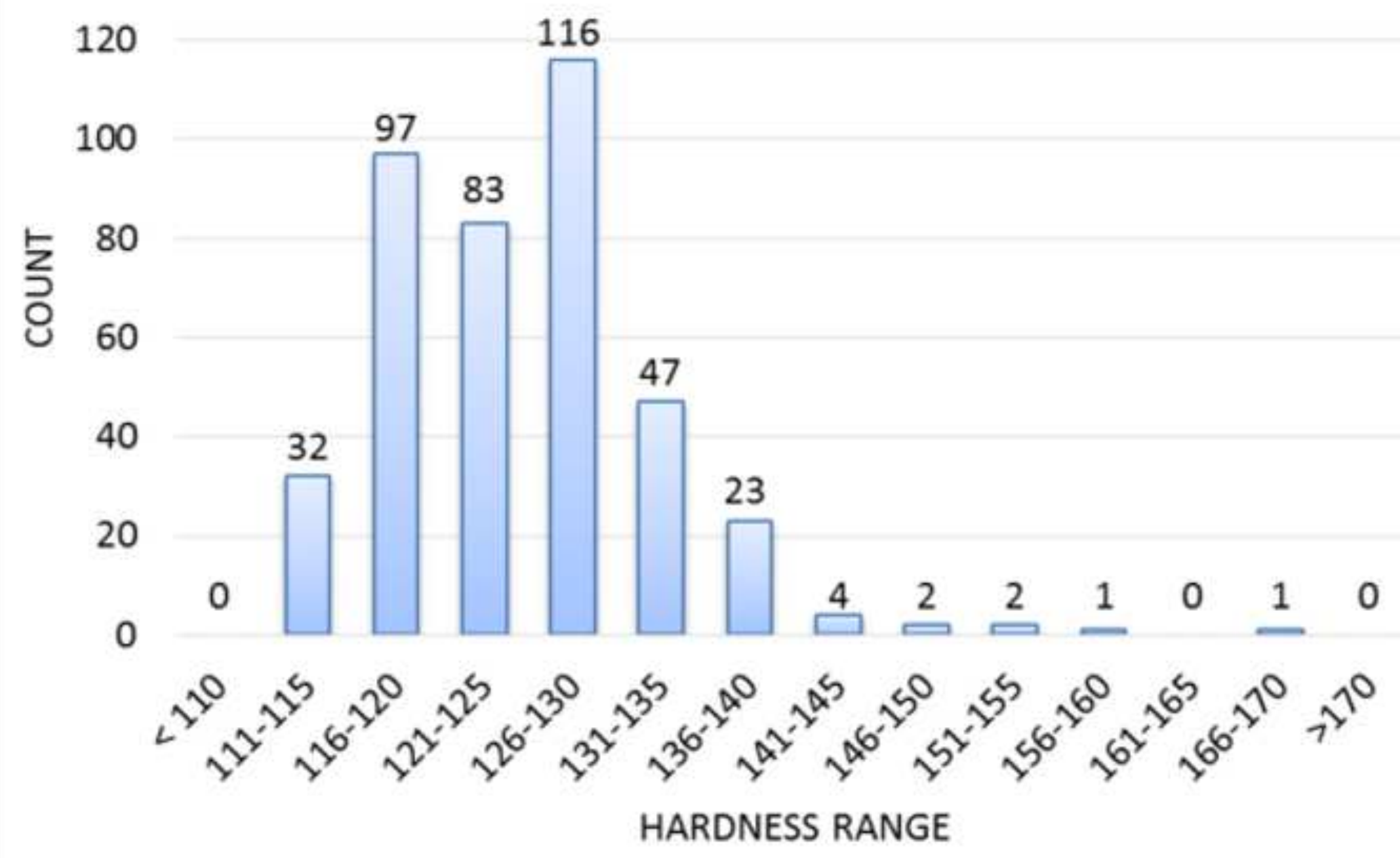




\section{Hot Reheat - Outage 1}

18

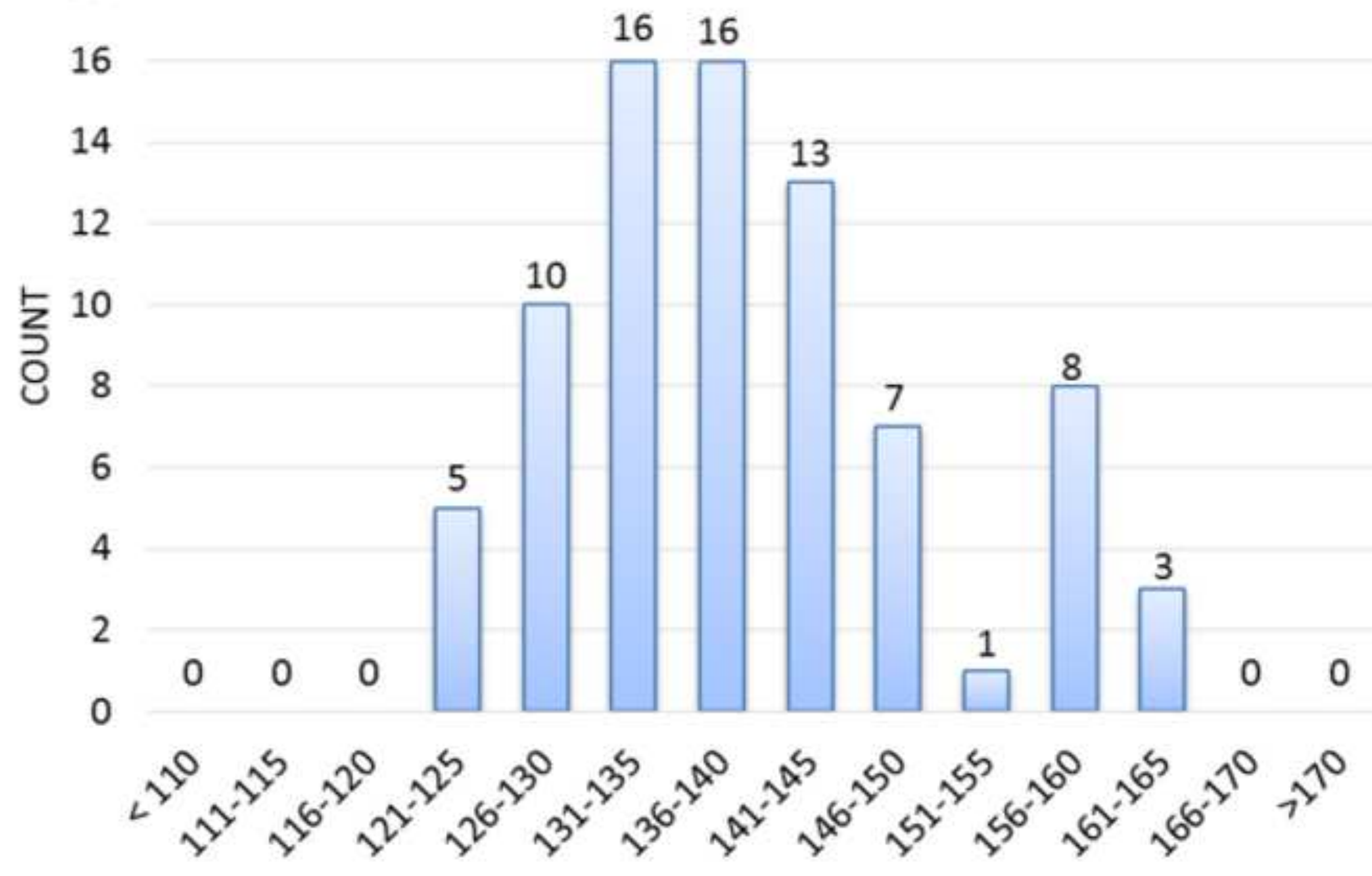

HARDNESS RANGE 


\section{Hot Reheat - Outage 2}

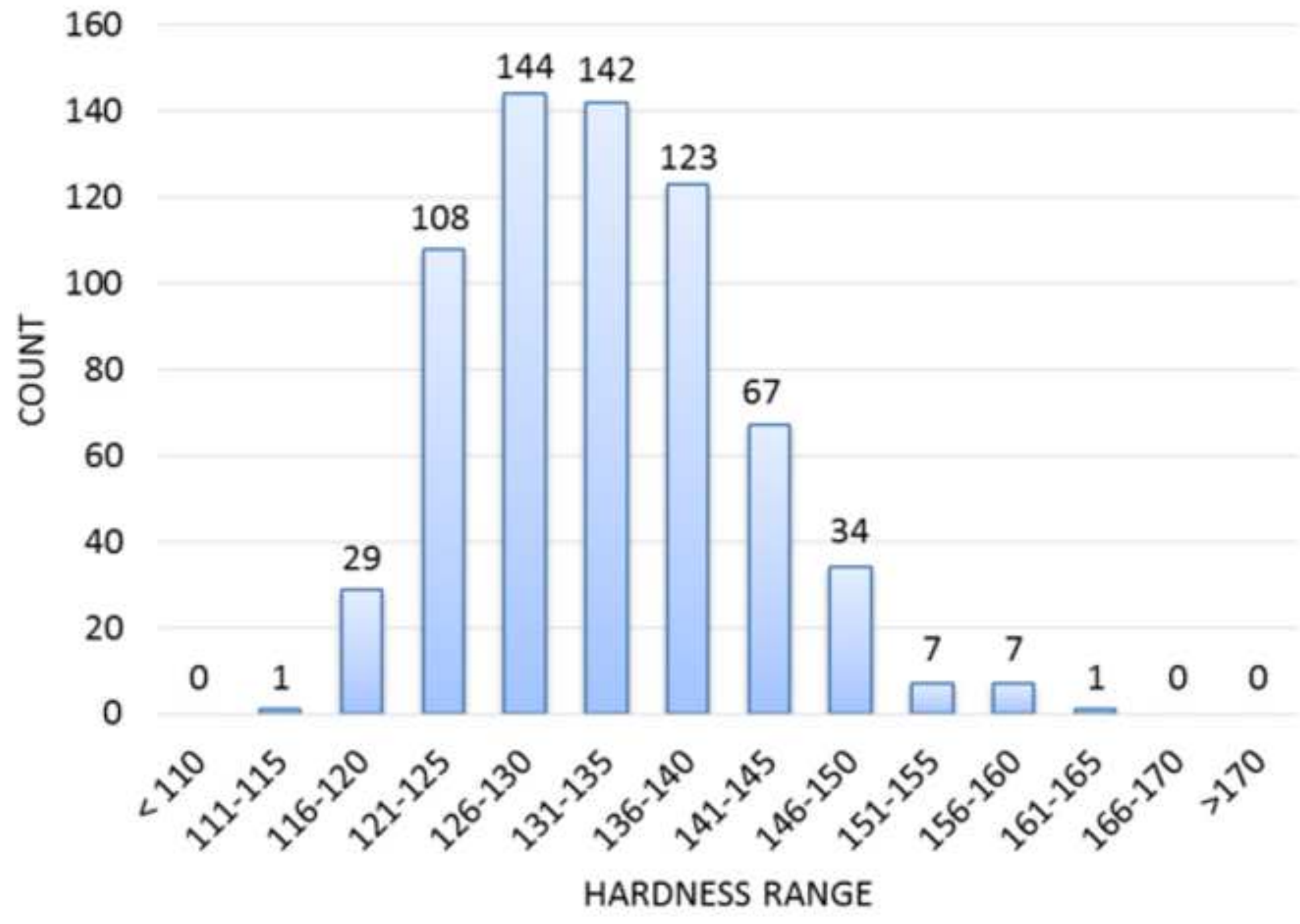


Main Steam HV vs. Replica (Outage 1)

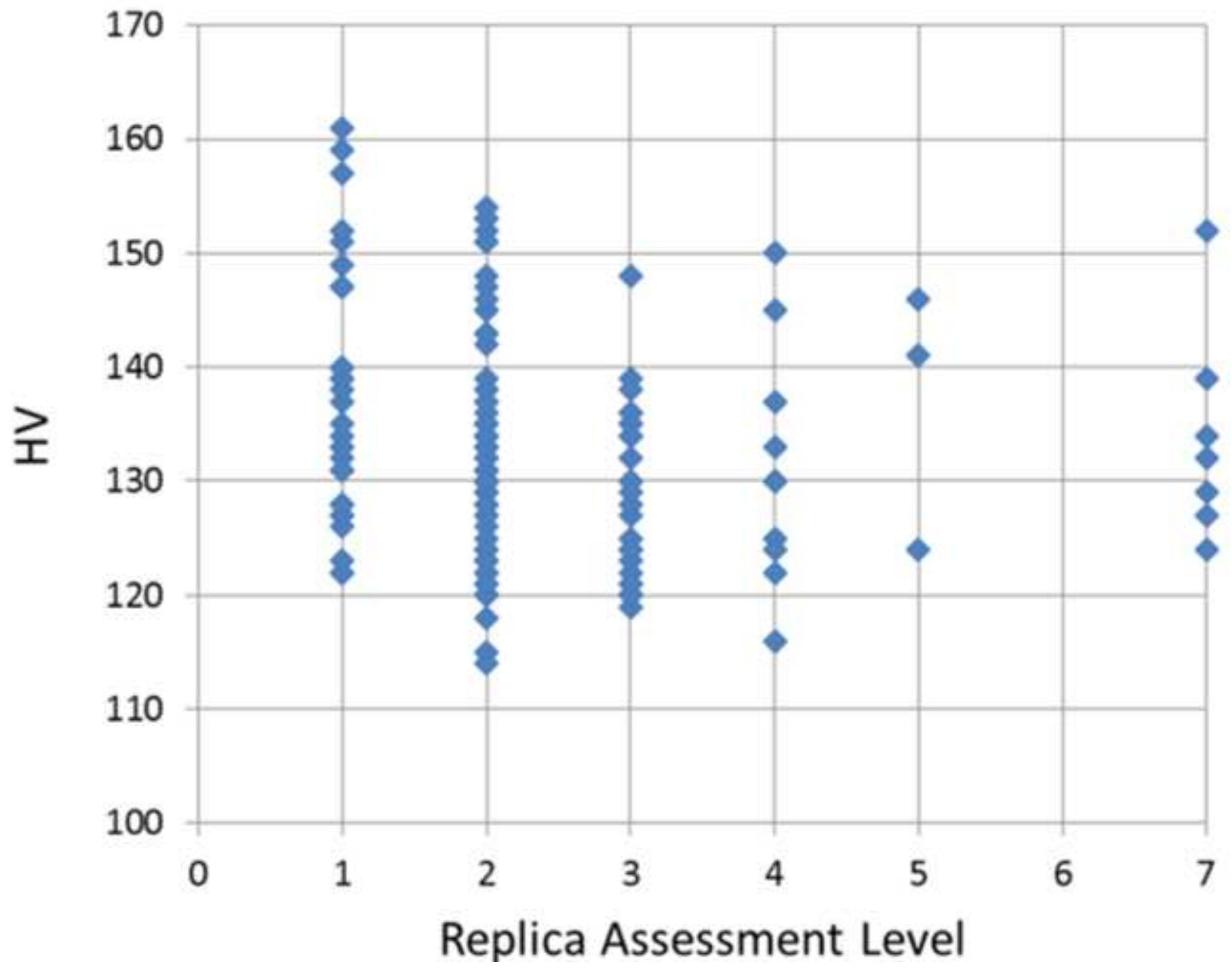


Main Steam HV vs. Replica (Outage 2)

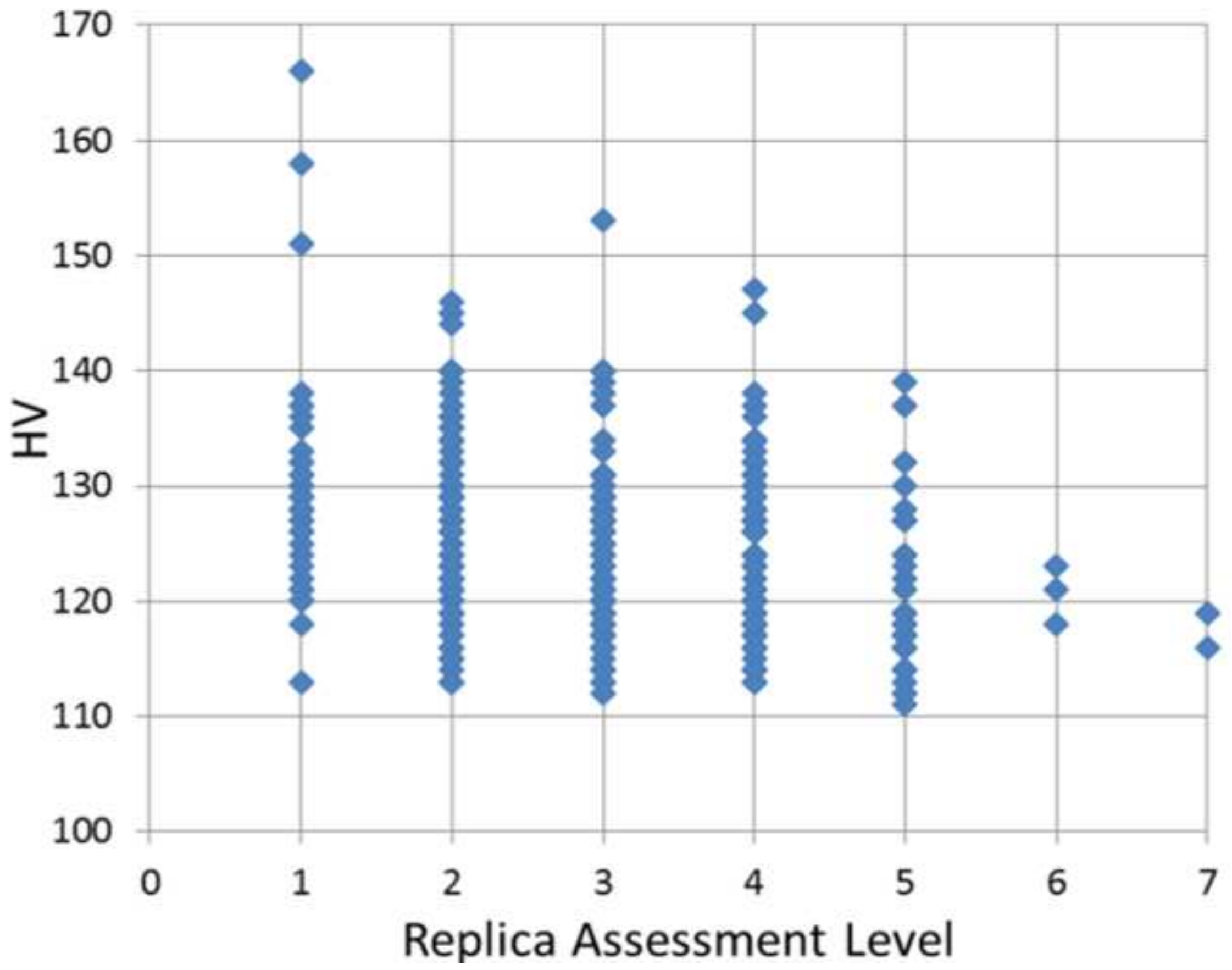


Hot Reheat HV vs. Replica (Outage 1)

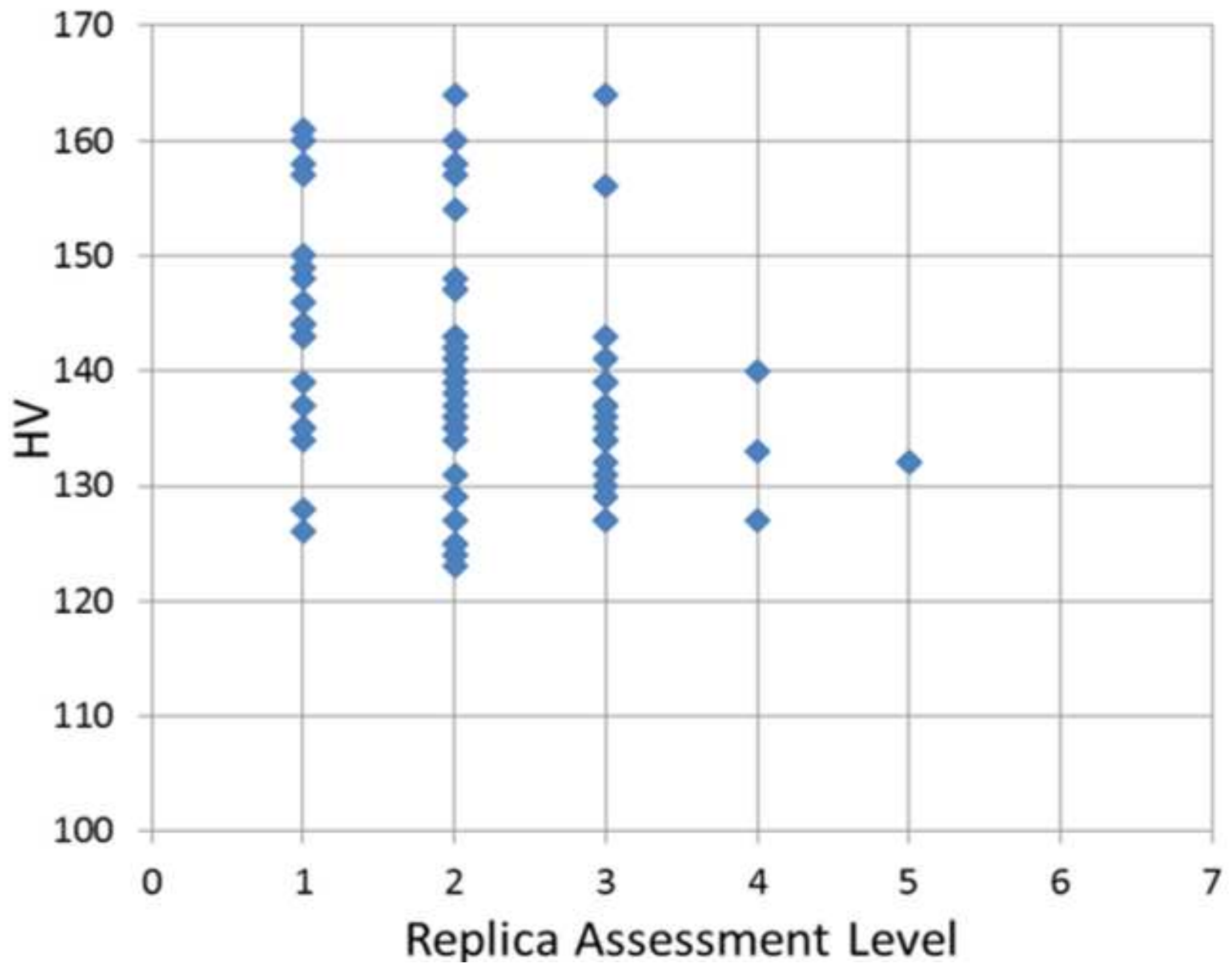




\section{Hot Reheat HV vs. Replica (Outage 2)}

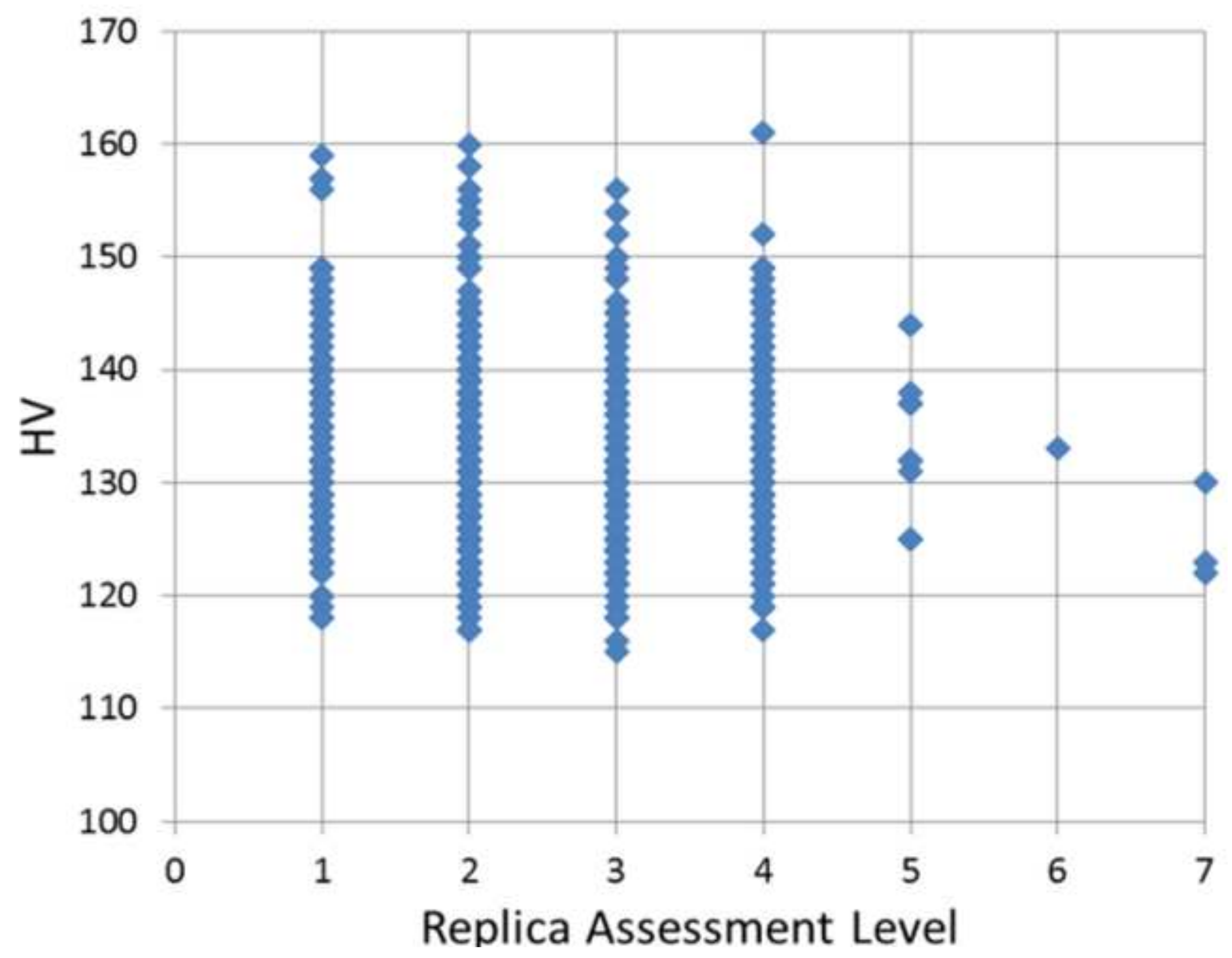




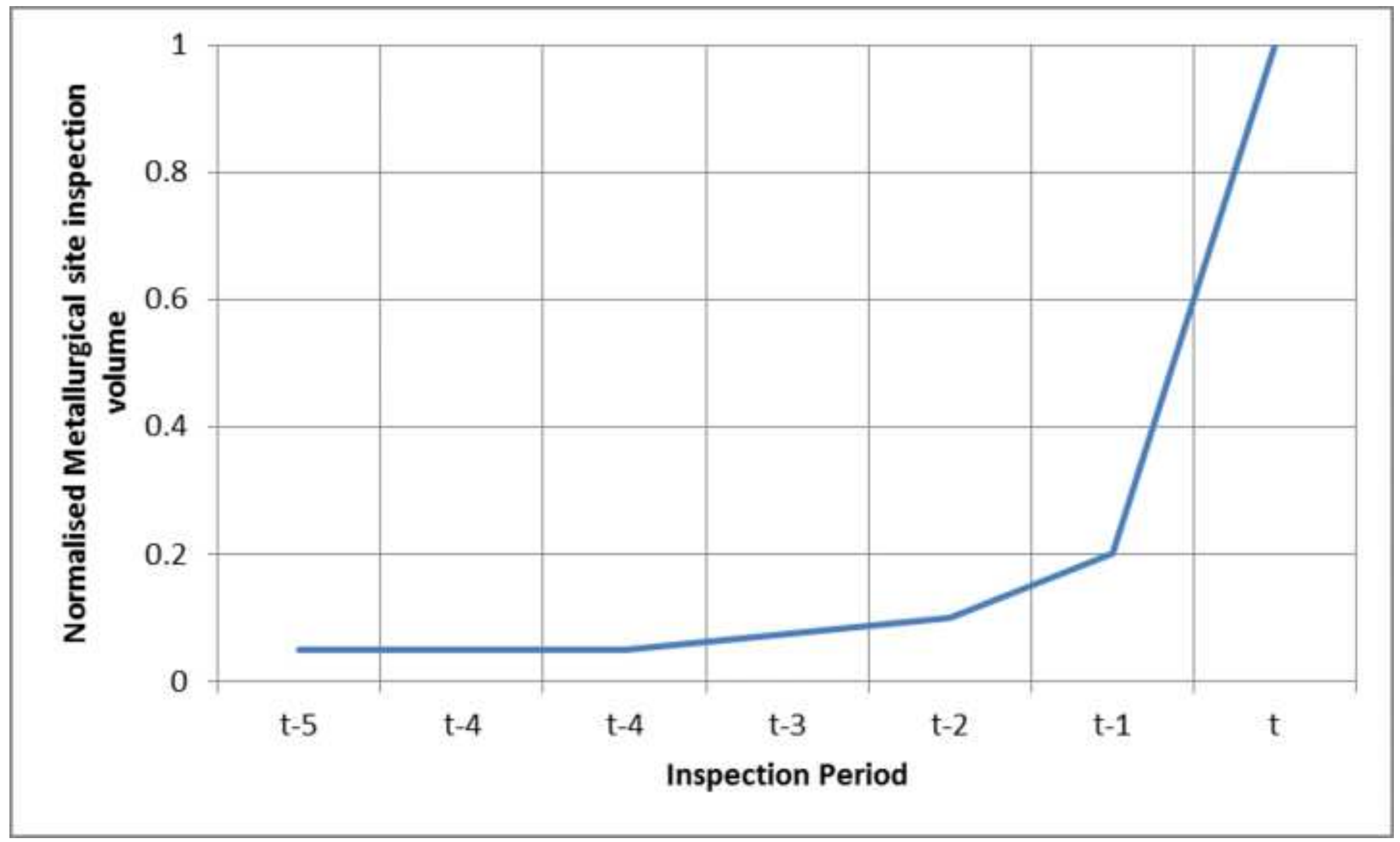




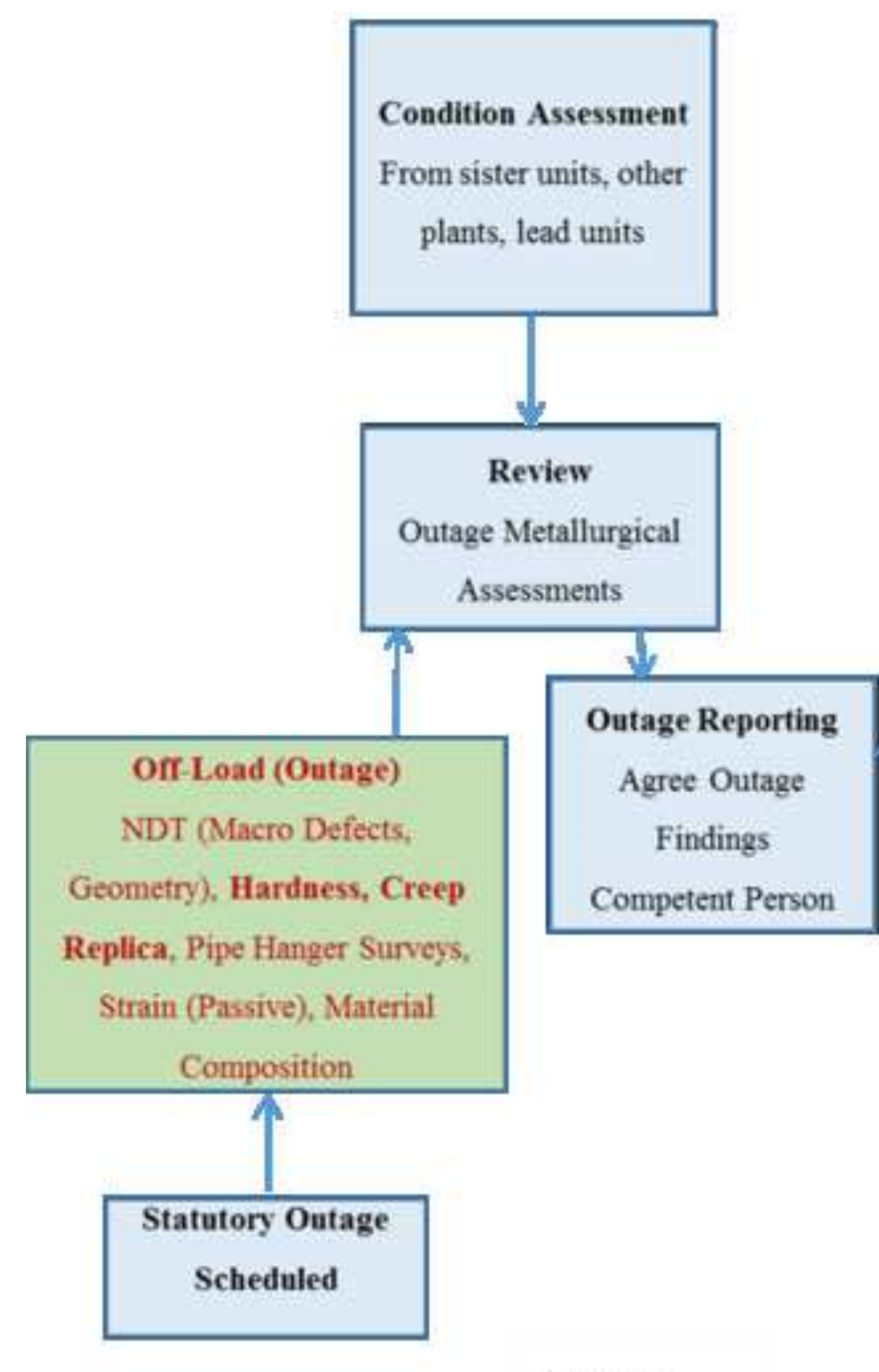

Outage

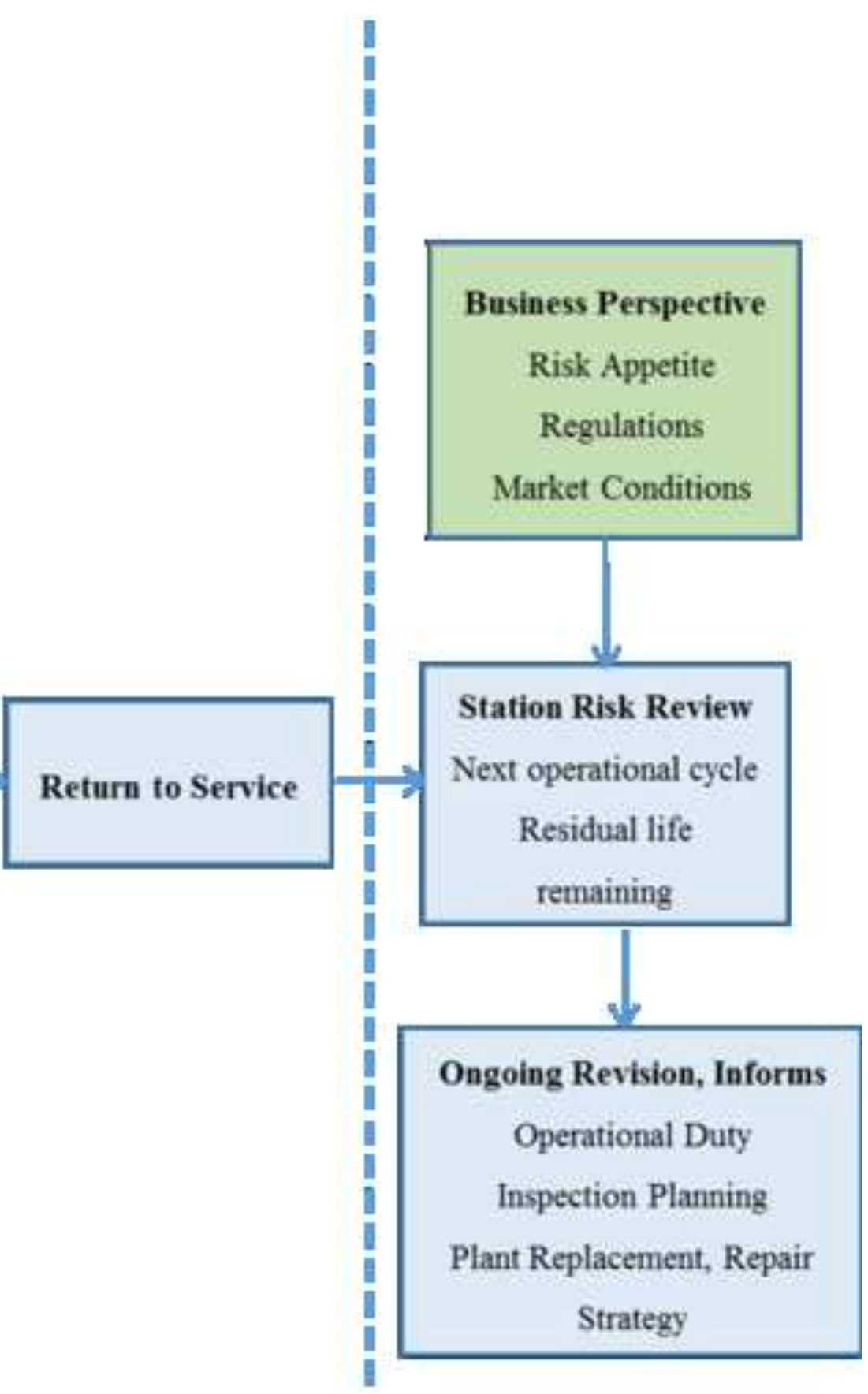

Tranciton

Business as usual 


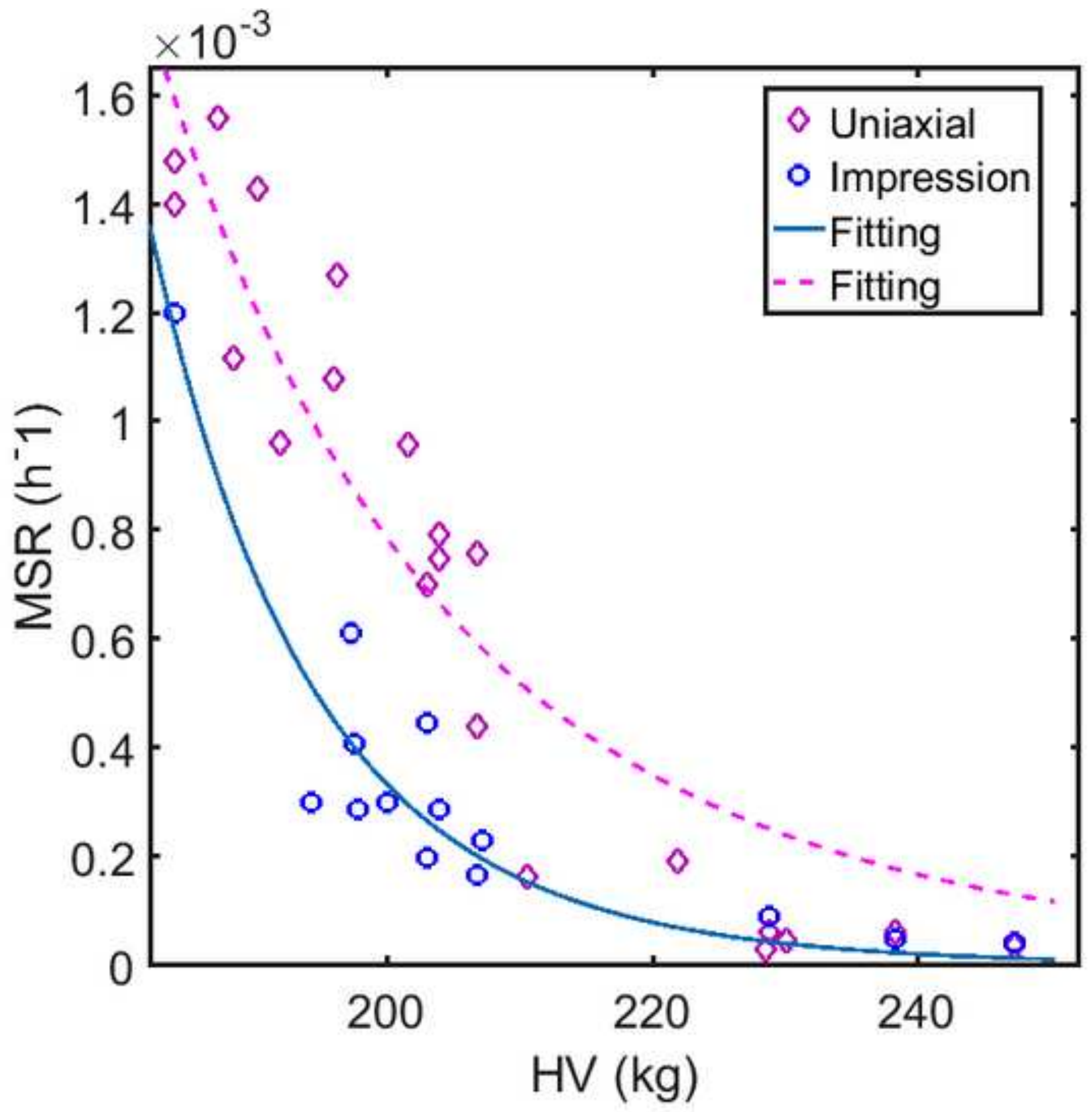




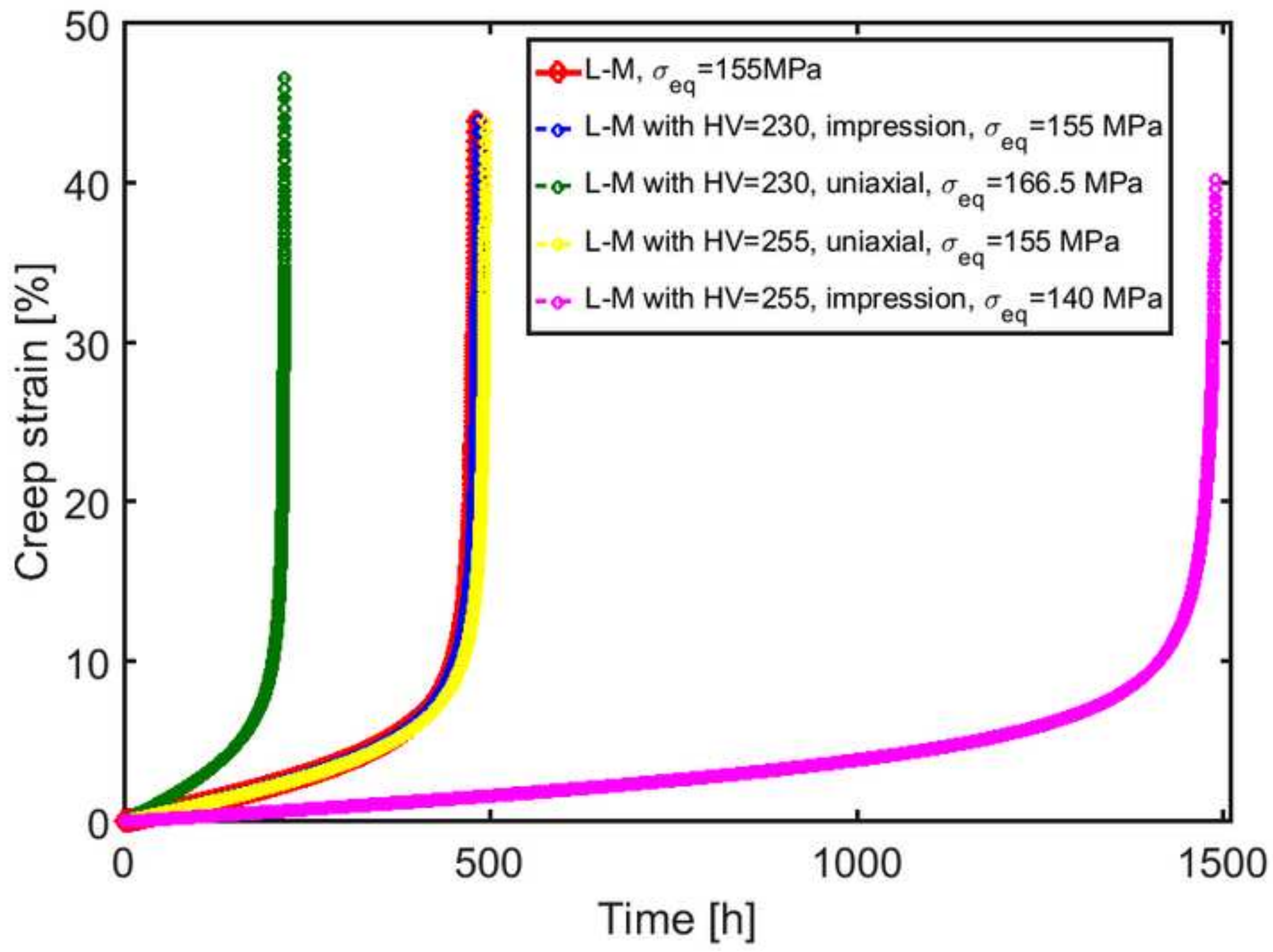




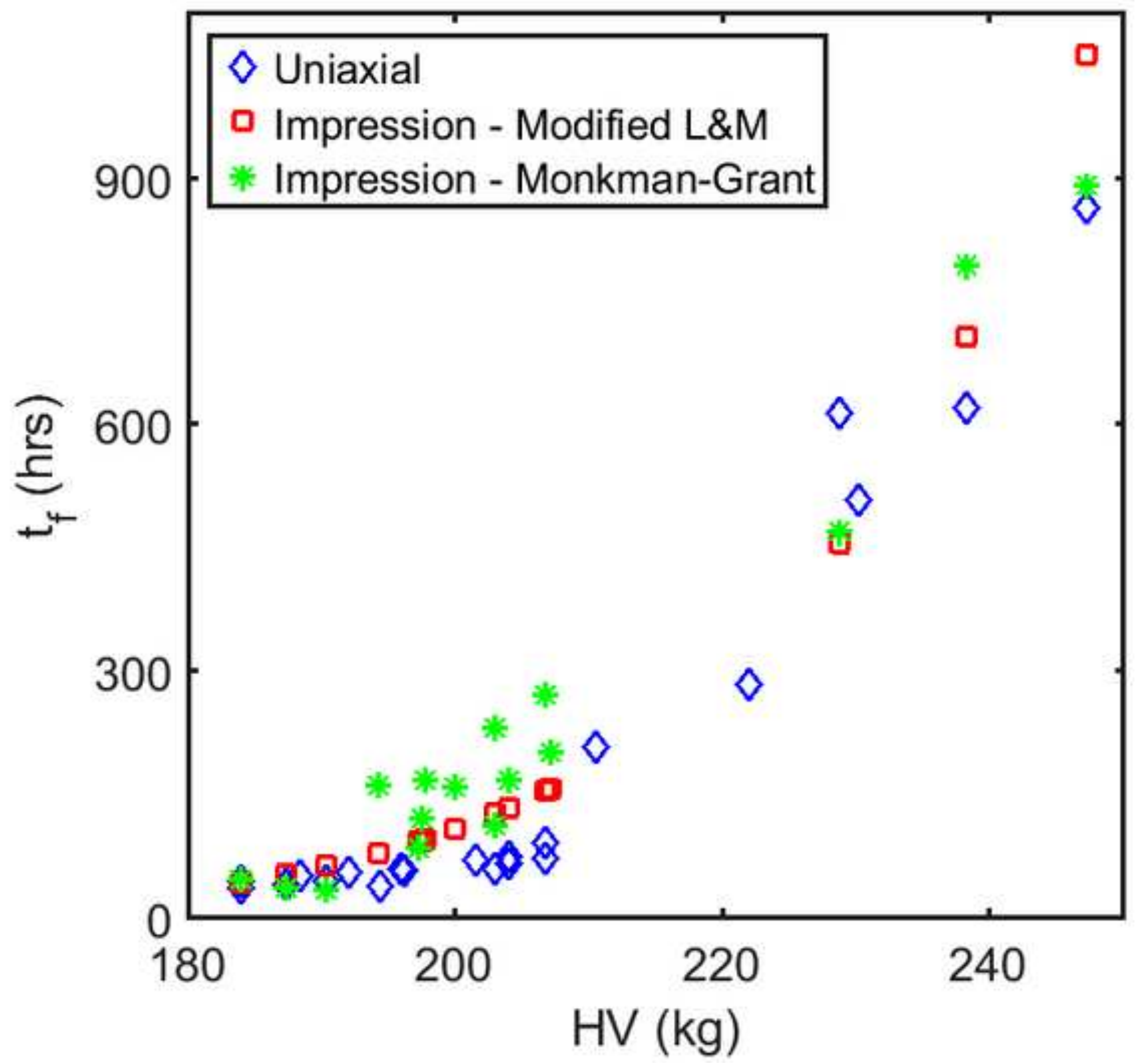



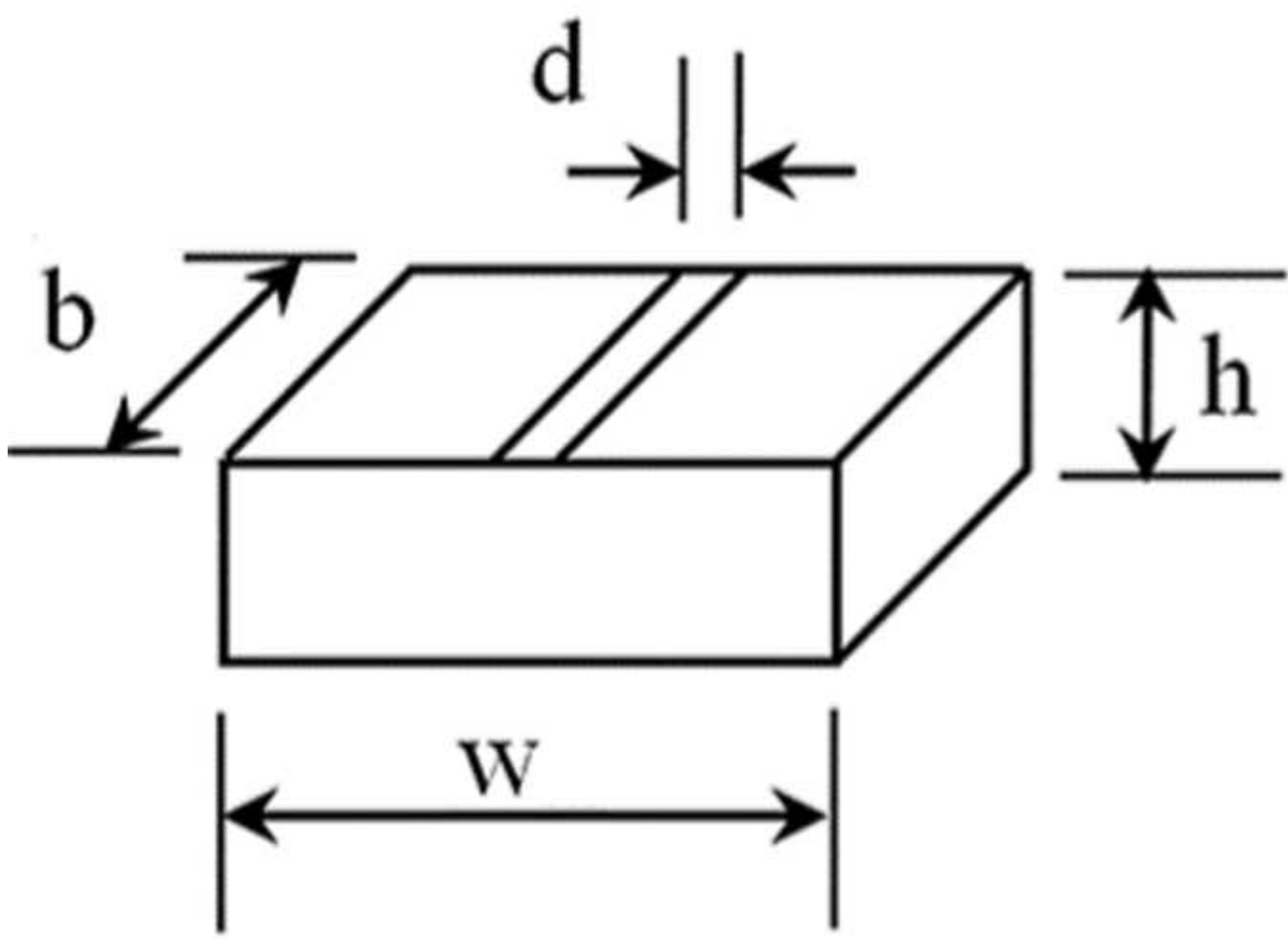


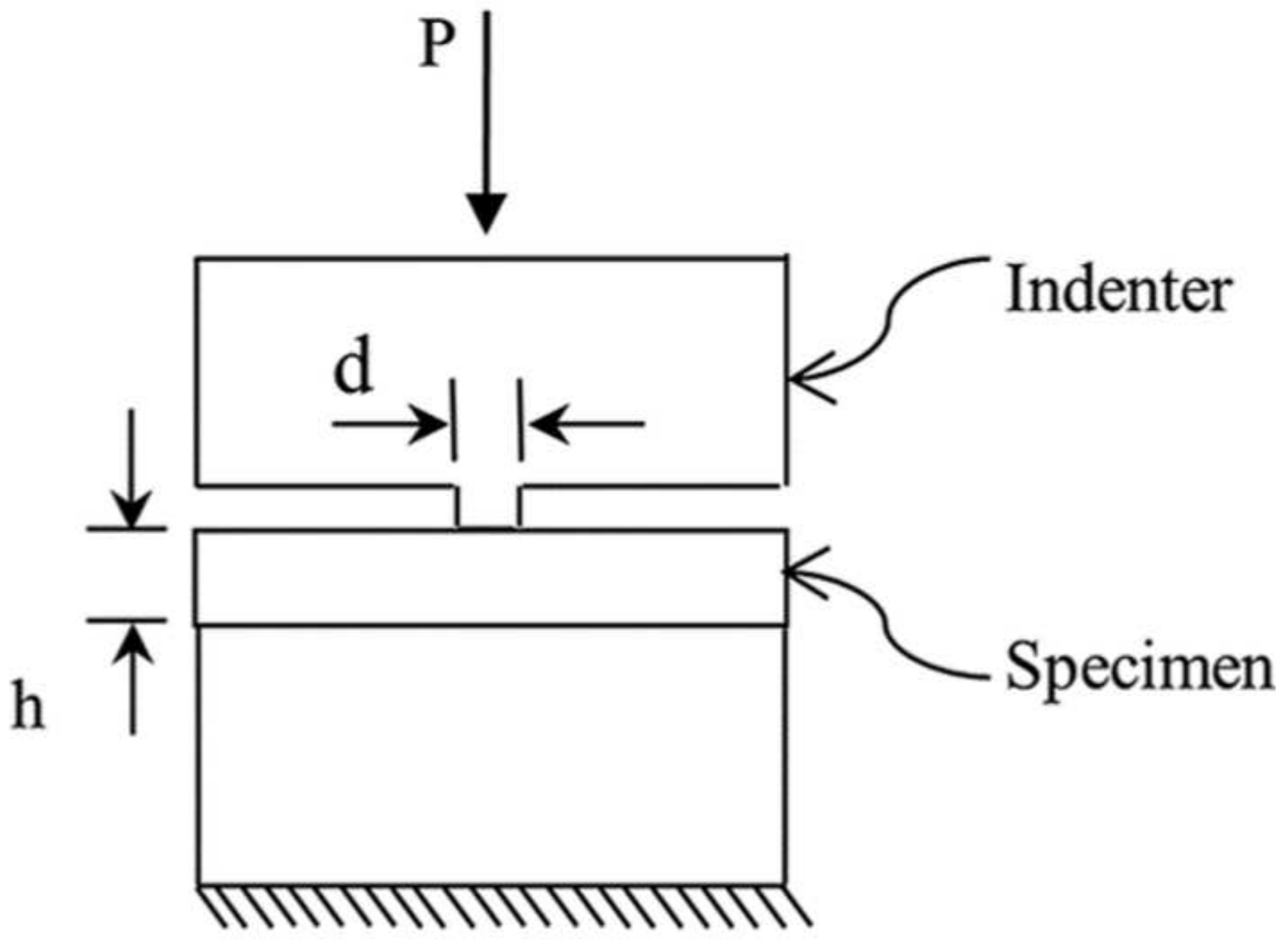

